
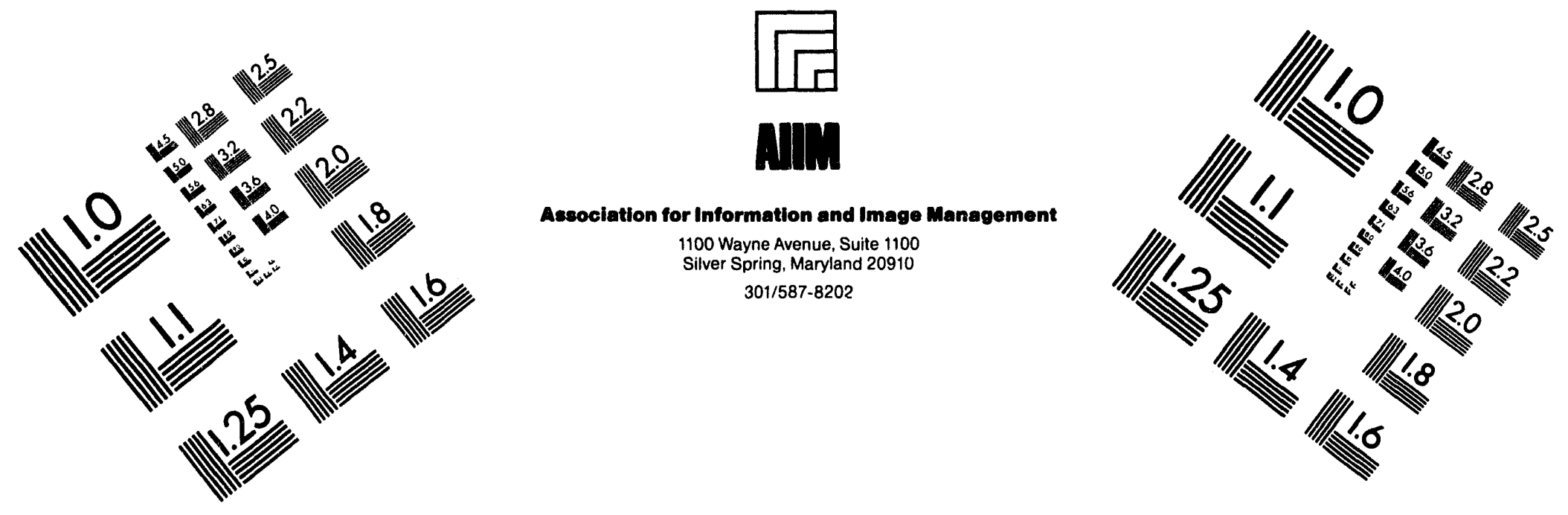

\title{
Centimeter
}

$\begin{array}{llllllllllllllll}1 & 2 & 3 & 4 & 5 & 6 & 7 & 8 & 9 & 10 & 11 & 12 & 13 & 14 & 15 & \mathrm{~mm}\end{array}$

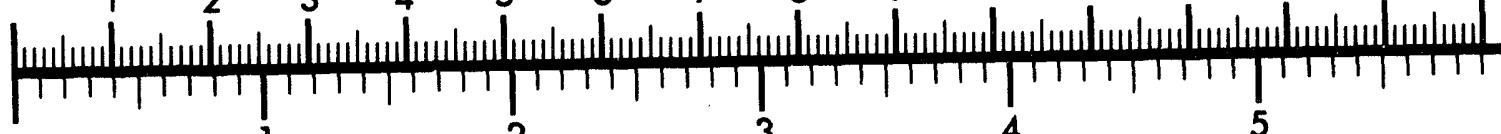

Inches
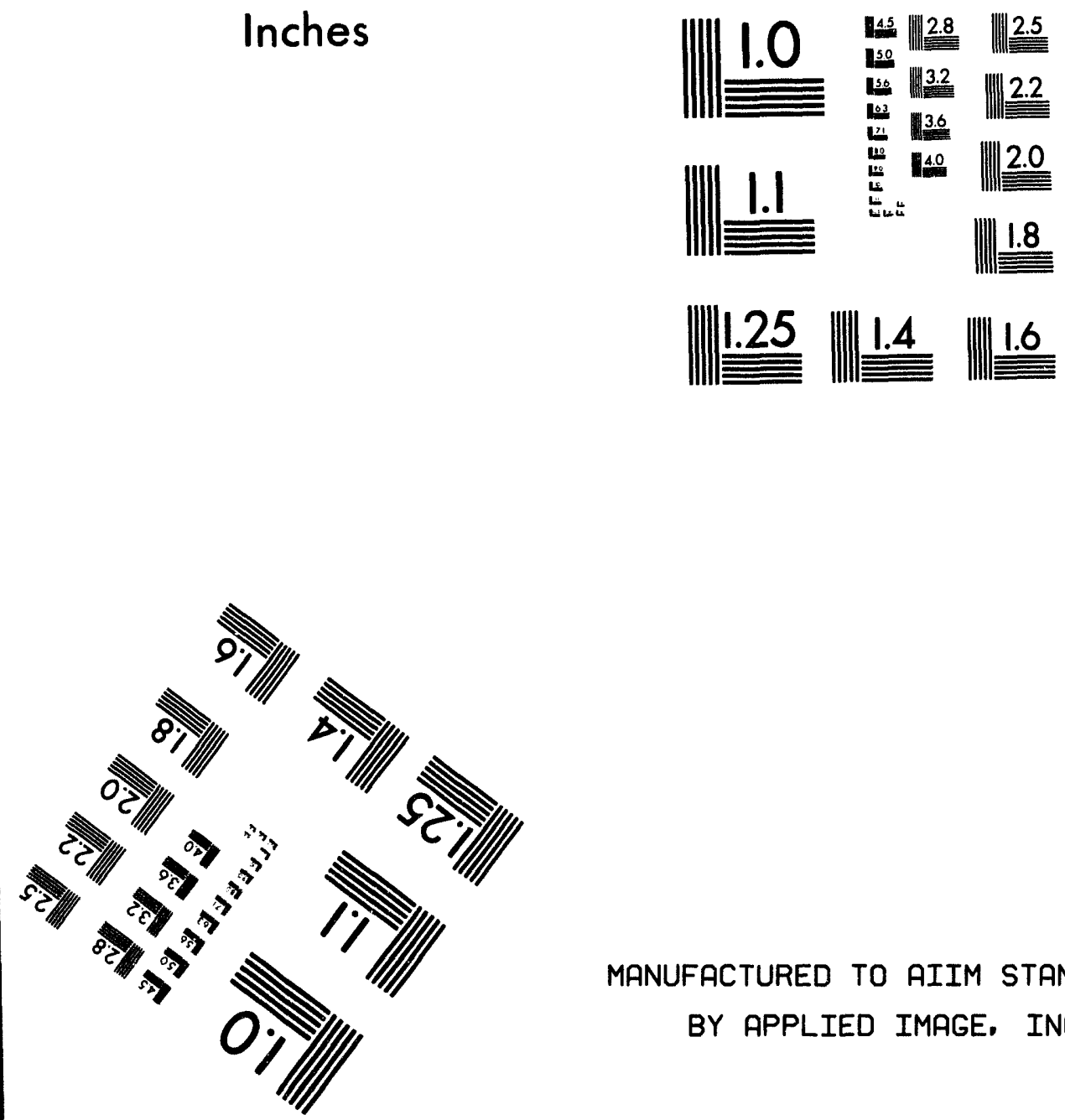

MANUFACTURED TO AIIM STANDARDS

BY APPLIED IMAGE, INC.

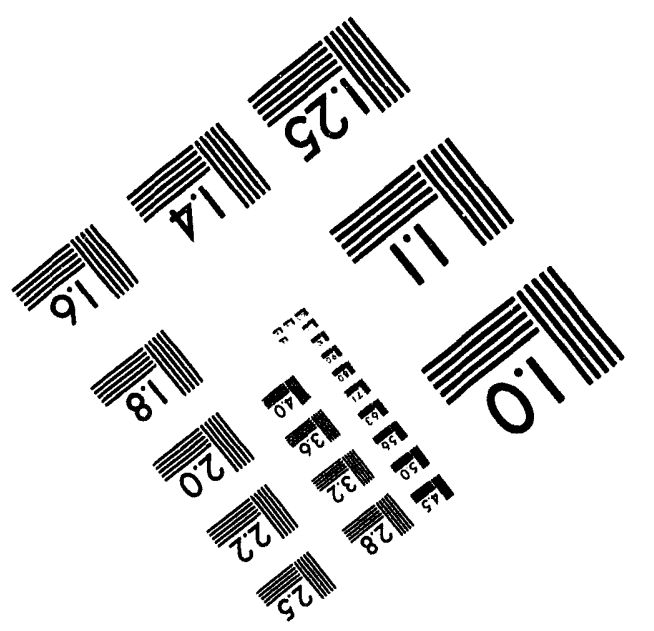



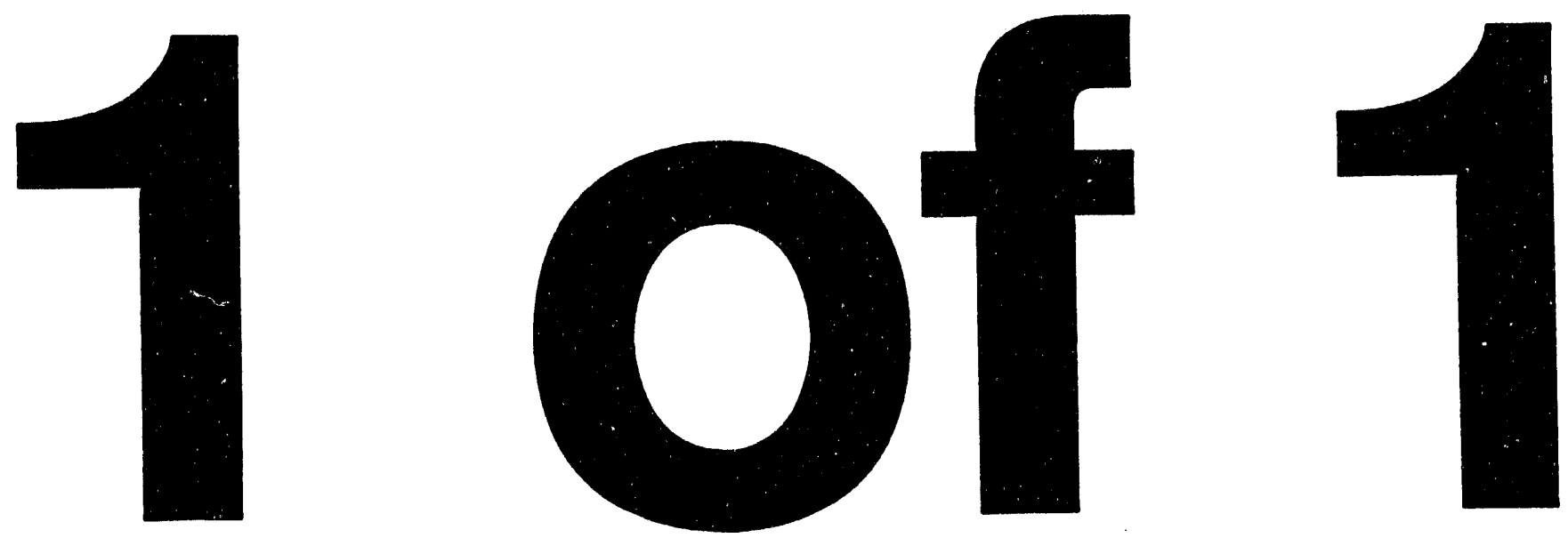
EGG-FSP-11037

ITER/US/93/TE/SA-18

\section{Vacuum System Operating Experience Review For Fusion Applications}

L. C. Cadwallader

Published March 1994

Idaho National Engineering Laboratory EG\&G Idaho, Inc. Idaho Falls, ID $\mathbf{8 3 4 1 5 - 3 8 8 0}$

Prepared for the

U.S. Department of Energy Office of Energy Research Under DOE Field Offlce, Idaho

Contract No. DE-AC07-76ID01570 


\begin{abstract}
This report presents a review of vacuum system operating experiences from particle accelerator, fusion experiment, space simulation chamber, and other applications. Safety relevant operating experiences and accident information are discussed. Quantitative order-of-magnitude estimates of vacuum system component failure rates and accident initiating event frequencies are presented for use in risk assessment, reliability, and availability studies. Safety concerns with vacuum systems are discussed, including personnel safety, foreign material intrusion, and factors relevant to vacuum systems being the primary confinement boundary for tritium and activated dusts. This information should be useful to fusion system designers and safety analysts, such as the team working on the Engineering Design Activities for the International Thermonuclear Experimental Reactor.
\end{abstract}




\section{SUMMARY}

This report is an overview of vacuum system operating experiences from particle accelerators, existing fusion experiments, and other facilities that use high vacuum systems. This report is not a chronicle of all vacuum system problems, but rather a guide to the persistent problems that are discussed in the literature. Table S-1 gives a qualitative list of these problems. While vacuum systems have not been a major cause of downtime at the major fusion experiments, they are growing in importance because they are the primary boundary for radioactive tritium fuel and for the induced radioactivity in the fusion vacuum system (activated dusts). More regulatory review of vacuum systems is expected as fusion systems grow more robust. This report, and others like it, will help to either prove that meaningful data can be generated for fusion, or to generate enough controversy over these values that will motivate equipment vendors and existing experiment operators to develop more accurate data sets.

Accidents, both real and postulated, are discussed. Safety concerns with vacuum systems are also briefly discussed. Then, vacuum system component failure rate estimates are made for a variety of components. The failure rate values presented here apply to fusion experiments, either because (a) the data originated from existing fusion experiments, (b) the data from non-fusion experiments have been corrected to account for the more severe fusion environment, or (c) the data for the component in question from non-fusion sources would not have any increase because of application in a fusion vacuum system. The component failure raie results are given in Table S-2. The assumptions, definitions of component size, leak rate, etc., are given in Chapter 5.

The report concludes with some estimates of vacuum system initiating event frequencies. These frequencies can be used as scoping values on future generation machines, such as the International Thermonuclear Experimental Reactor (ITER), because the frequency values are from either the Next European Torus (a machine almost as large as ITER) or the values were generated for ITER itself. One area, the vacuum vessel wall failure frequency, must be further addressed. The wall failure, or vessel breach, values presented here are judgment only.

This report is the third in a series of reports to harvest existing data for support of reliability in design, reliability analysis, and risk assessment. The initial reports dealt with magnets and cryogenic systems. This report can also support the magnet systems, since a vacuum will be used for thermal insulation. Future work will also support the magnet work by examining electrical power supply systems. 
Table S-1. Summary of vacuum component faults cited in the literature

Valve internal seal leaks

Bellows leaks

Flange cracking leaks

Personnel leaving foreign materials inside the vacuum vessel

Improperly tighten flanges

Valve positions not verified, causing damage to system

Gas other than helium being supplied to helium leak detectors

Dust intrusion into valve seats and seals causes leaks

Window, electrical feedthrough, weld, bellows, flange, and vacuum gauge leaks

Electrical feedthroughs experiencing electrical discharges in low pressure air

Valve bonnet leaks

Inadvertent opening of valve to atmosphere

Objects in magnet fringe field impacting the torus or shifting position to shear vacuum lines

Diagnostics tearing bellows due to misalignment

Diagnostic window cracks, bloating, or other weaknesses that allow air ingress

Water inleakage from metallurgy faults, bad welds

Intrusion of dust into the vacuum system

Loss of tension in flange bolts, leading to air leaks

Braze failure at ceramic to metal interface, leading to air leaks

Rotary feedthroughs leaking badly 
Table S-2. Vacuum system component failure rate estimates

$\begin{array}{lll}\text { Component } & \text { Eailure rate } & \text { Associated error }\end{array}$

Large turbopump

ceramic bearing fails to operate metal bearing fails to operate casing leakage

Mechanical roughing pump high speed pump (vane, etc.) fails to operate casing leak

roots blower fails to operate roots blower casing leak

Cryosorption roughing pump fails to operate

casing leak

Large cryopump

fails to operate (plugged)

leak cryogen into vacuum chamber

casing leak

Small titanium sublimation pumr

fails to operate

(premature filament open circuit)

feedthrough leak

casing leak

Non-evaporable getter ( $\mathrm{Zr}-\mathrm{Al})$ pump

fails to operate

casing leak
9E-06/hour

$1.3 \mathrm{E}-05 /$ hour

5E-03/year

$1.5 \mathrm{E}-05 /$ hour

5E-03/year

$1.5 \mathrm{E}-05 /$ hour

$5 \mathrm{E}-06 /$ hour (upper bound)

Low failure rate; use availability of liquid nitrogen supply, since zeolite can continue to function indefinitely under good conditions

5E-03/year error factor 10

2E-06/hour

error factor 10

2E-05/hour

error factor 1.7

7E-06/year

error factor 10

9E-07/hour

error factor 1.7

7.4E-05/hour

error factor 1.4

3E-05/year

error factor 10
9E-07/hour (upper bound)

3E-05/year error factor 10 


\section{Component}

Small ion pump

diode pump fails to operate

casing leak

feedthrough leak

Large ejector pump

all modes

(air leak, working fluid leak, and fail to operate [plugged])

Metal gasket flanges

160 to $215 \mathrm{~mm}$ diameter leakage

295 to $360 \mathrm{~mm}$ diameter leakage

$1 \mathrm{~m}$ and larger diameter leakage

flange bolt

Electrical feedthrough for diagnostics

leakage

Metal bellows

leakage

Bayard Alpert hot filament ionization gauge

all modes

(same value for failure to operate

and tubular gauge leakage)

Penning cold cathode ionization gauge

all modes

(fail to operate, leakage)

Pirani gauge

fail to operate

leakage
Eailure rate

Associated error

2E-05/hour

error factor 3

3E-05/year

error factor 10

1.5E-04/hour

error factor 1.4

7E-06/hour

error factor 10

1E-03/year

error factor 3

6E-02/year

error factor 3

5E-01/year

error factor 10

2E-08/hour

error factor 10

5E-04/hour

error factor 1.4

8E-04/hour

error factor 1.6

$6 \mathrm{E}-03 /$ year

error factor 2.2

6E-03/year (upper bound)

3E-05/hour

6E-03/year error factor 10

error factor 2.2 
Rough vacuum gauges

fail to operate

leakage
1E-04/hour

1E-03/year error factor 10

error factor 3

Vacuum windows (quartz optical viewports) leakage

1.4E-06/discharge or

1.4E-06/hour

error factor of 1.8

this value should be used for other windows (metal or ceramic) until future data on windows becomes available.

Valves

fail to operate on demand

1E-04/demand

error factor 2

(fail to open or fail to close)

spurious open or close motor operated air operated

5E-08/hour

error factor 10

3E-06/hour error factor 10

solenoid operated

5E-07/hour

error factor 10

external air leakage

2E-07/hour

error factor 10

internal leakage across the seat

3E-06/hour

error factor 30

Vacuum piping and ducts

piping leakage

1E-08/hour-m

error factor 30

tank leakage

1E-08/hour

error factor 30

(rupture values are a factor of 100 lower than the leakage estimates)

Vacuum vessel

wall breach

5.7E-05/year (for 25\% availability)

Filters

electrostatic filter leakage

electrostatic filter fail to operate

3E-07/hour

error factor 10

1E-05/hour

error factor 10

solid filter leakage

3E-07/hour

error factor 10

solid filter fail to operate

7E-06/hour

error factor 10 


\section{ACKNOWLEDGMENTS}

This report would not have been possible without the help of several people. First, the INEL technical library staff did literature searches, helped procure many reports, books, and conference proceedings. The people whom I interviewed, Dr. George Martin and Dr. Peter Taylor were very helpful. My thanks also go to Dr. David Petti and Mr. Tom McDonald for their review. $\mathrm{Also}$, this work was funded by the International Thermonuclear Experimental Reactor (ITER) design activity. 


\section{CONTENTS}

Abstract $\ldots \ldots \ldots \ldots \ldots \ldots \ldots \ldots \ldots \ldots \ldots \ldots \ldots \ldots \ldots \ldots \ldots \ldots \ldots$

Summary $\ldots \ldots \ldots \ldots \ldots \ldots \ldots \ldots \ldots \ldots \ldots \ldots \ldots \ldots \ldots \ldots \ldots \ldots$

Acknowledgments $\ldots \ldots \ldots \ldots \ldots \ldots \ldots \ldots \ldots \ldots \ldots \ldots \ldots \ldots \ldots$ viii

Nomenclature $\ldots \ldots \ldots \ldots \ldots \ldots \ldots \ldots \ldots \ldots \ldots \ldots \ldots \ldots \ldots$

1. Introduction $\ldots \ldots \ldots \ldots \ldots \ldots \ldots \ldots \ldots \ldots \ldots \ldots \ldots \ldots \ldots \ldots$

2. Vacuum System Operating Experiences $\ldots \ldots \ldots \ldots \ldots \ldots \ldots \ldots \ldots \ldots$

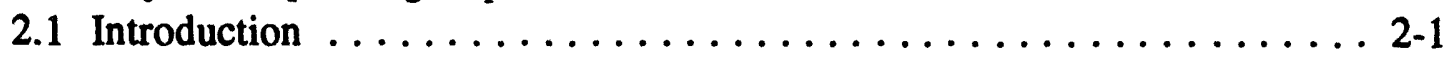

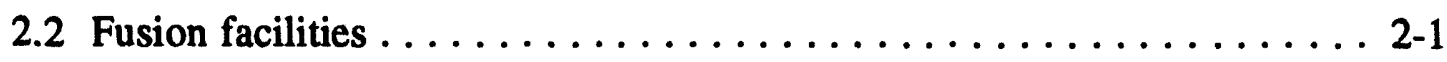

2.3 Accelerator facilities . . . . . . . . . . . . . . . . .

2.4 Space simulation chambers and other applications . . . . . . . . 2-9

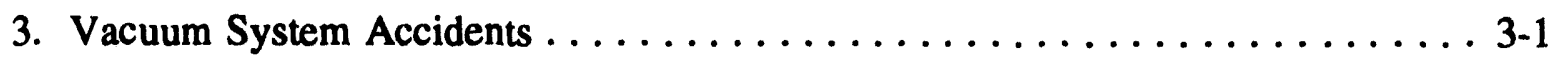

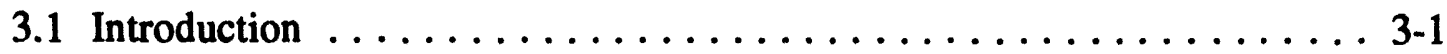

3.2 Air inleakage . . . . . . . . . . . . . . . . . . 3-1

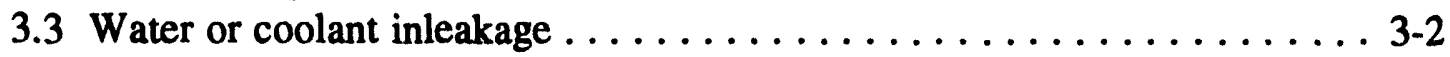

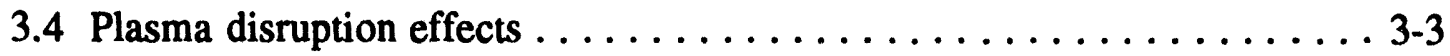

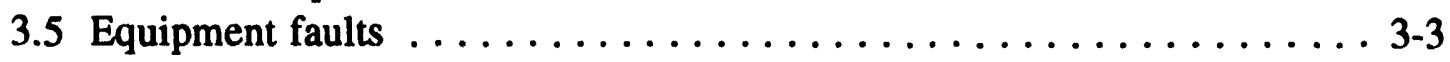

4. Vacuum Safety Concerns . . . . . . . . . . . . . . . . . . 4-1

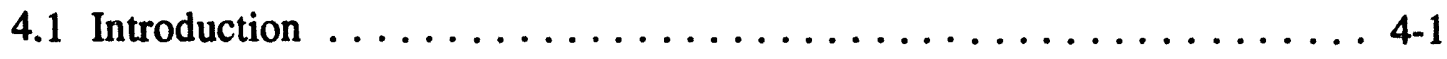

4.2 Vacuum vessel irradiation . . . . . . . . . . . . . . . 4-1

4.3 Mechanical vibrations and stresses $\ldots \ldots \ldots \ldots \ldots \ldots \ldots \ldots$ 4-2

4.4 Electromagnetic stress . . . . . . . . . . . . . . . . . 4-2

4.5 Runaway electrons $\ldots \ldots \ldots \ldots \ldots \ldots \ldots \ldots \ldots . \ldots \ldots$ 4-2

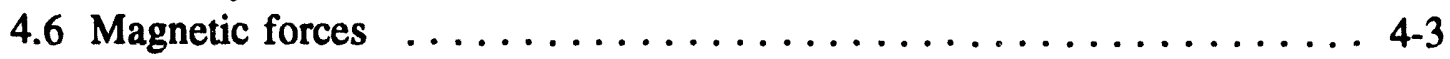

4.7 Pump fire and explosion hazards $\ldots \ldots \ldots \ldots \ldots \ldots \ldots \ldots \ldots$ 4-3

4.8 Personnel safety concerns . . . . . . . . . . . . . . . . 4-4

5. Vacuum System Component Failure Rates $\ldots \ldots \ldots \ldots \ldots \ldots \ldots \ldots$

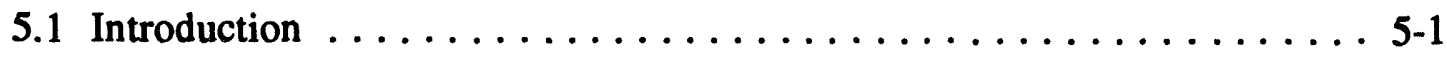

5.2 Pumps ......................... $5 . \ldots \ldots$

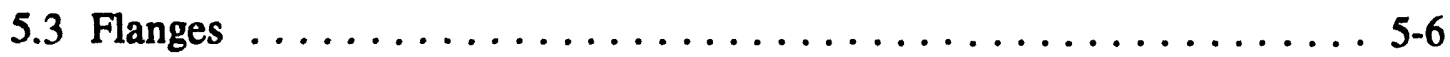

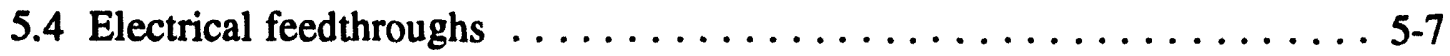

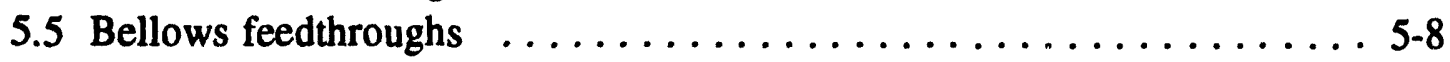

5.6 Vacuum gauges $\ldots \ldots \ldots \ldots \ldots \ldots \ldots \ldots \ldots \ldots \ldots$

5.7 Vacuum windows $\ldots \ldots \ldots \ldots \ldots \ldots \ldots \ldots \ldots \ldots \ldots$ 


\section{CONTENTS \\ (continued)}

5. Vacuum System Component Failure Rates (continued)

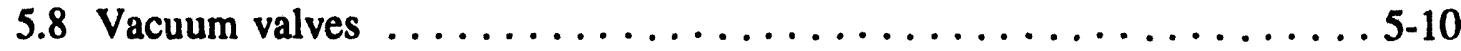

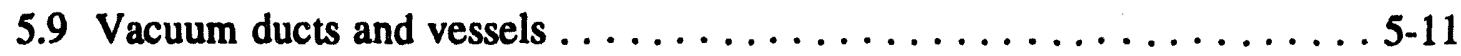

5.10 Other components . . . . . . . . . . . . . . . . . .

6. Vacuum System Initiating Events $\ldots \ldots \ldots \ldots \ldots \ldots \ldots \ldots \ldots \ldots \ldots, 6 \ldots \ldots$

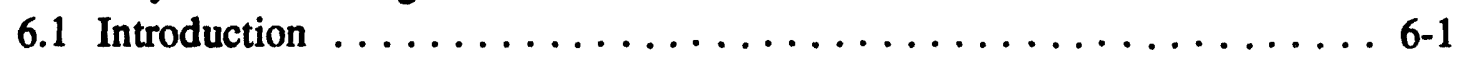

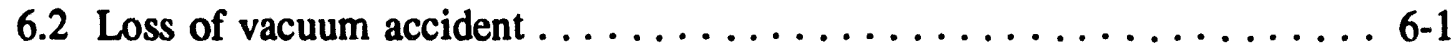

6.3 Loss of coolant accident $\ldots \ldots \ldots \ldots \ldots \ldots \ldots \ldots \ldots \ldots, 6,2$

6.4 Loss of flow accident $\ldots \ldots \ldots \ldots \ldots \ldots \ldots \ldots \ldots \ldots \ldots \ldots \ldots \ldots \ldots, 2$

6.5 Other events ........................ 6-3 


$\begin{array}{ll}\text { BAG } & \text { Bayard-Alpert Gauge } \\ \text { CERN } & \begin{array}{l}\text { Center for European Research Nucleaire in Geneva, Switzerland } \\ \text { demand }\end{array} \\ \text { EDA } & \begin{array}{l}\text { Engineering Design Activities for ITER } \\ \text { grams }\end{array} \\ \text { g } & \text { hour } \\ \text { h } & \text { initiating event } \\ \text { IE } & \text { International Thermonuclear Experimental Reactor } \\ \text { ITER } & \text { Joint European Torus } \\ \text { JET } & \text { Japan Torus, } 60 \mathrm{~m}^{3} \text { volume } \\ \text { JT-60 } & \\ \text { LEP } & \text { Large Electron Positron Collider at CERN } \\ \text { LHe } & \text { Liquid helium } \\ \text { LOCA } & \text { Loss of Coolant Accident } \\ \text { LOFA } & \text { Loss of Flow Accident } \\ \text { LOVA } & \text { Loss of Vacuum Accident } \\ \text { LN2 } & \text { Liquid nitrogen } \\ \text { m } & \text { meter } \\ \text { m } 3 & \text { cubic meter } \\ \text { mm } & \text { millimeter } \\ \text { NET } & \text { Next European Torus } \\ \text { Pa } & \text { Pascal } \\ \text { rpm } & \text { revolutions per minute } \\ \text { s } & \text { second } \\ \text { SPS } & \text { Superconducting Positron Synchrotron at CERN } \\ \text { TFTR } & \text { Tokamak Fusion Test Reactor } \\ \text { Torr } & \text { pressure unit, equal to 133.3 Pa } \\ & \end{array}$




\section{VACUUM SYSTEM OPERATING EXPERIENCE REVIEW FOR FUSION APPLICATIONS}

\section{INTRODLCTION}

This report contains a review of vacuum system operating experiences for use by fusion system designers and safety analysts. Representative types of events found in published operating histories, safety concerns for vacuum systems and equipment, failure rates for vacuum components, and system failure frequencies are discussed. Vacuum systems are necessary for both inertial confinement and magnetic confinement approaches to fusion. Therefore, this report should be of interest to a wide group of designers and safety personnel.

Vacuum systems have evolved greatly over the course of fusion research. In the 1950's vacuum was typically maintained by hot oil diffusion pumps. Some of those pumps could be quite large, perhaps $4 \mathrm{~m}$ tall by $1 \mathrm{~m}$ diameter for large vacuum complexes. Those pumps could achieve good vacuum, but were reputed to have had difficulties with oil backstreaming into the vacuum chamber if they were not operated properly. While diffusion pumps are simple, reliable, and can be modified with baffles or traps to stop oil migration into systems, oil contamination is very detrimental to maintaining a good vacuum in the system. With prudent operation, diffusion pumps work well, but as vacuum technology progressed, ion, sublimation (getters), cryosorption, and then turbomolecular pumps began to be used for fusion systems since these types of pumps have less contamination concerns. These pumps are generally regarded as cleaner, and can sometimes generate higher vacuum than diffusion pumps. For this report, high vacuum is defined to be on the order of 0.13 to $1.3 \mathrm{E}-05 \mathrm{~Pa}$ (1E-03 to $1 \mathrm{E}-07 \mathrm{Torr}$ ). Ultrahigh vacuum is defined to be less than 1E-05 $\mathrm{Pa}$ (1E-07 Torr). However, the range of vacuum from atmospheric pressure to ultrahigh vacuum is considered here wherever practical, since most systems must provide for 'roughing' from atmospheric pressure down to the range where the sophisticated molecular flow pumps operate.

The discussion in this report is not intended to be a complete discussion on vacuum safety, nor is it a chronicle of all significant vacuum system failures and vacuum component failure rates. Resources are too limited for such a complete treatment. This work does give a representative view of vacuum experiences from a safety viewpoint; it cites items to be conscious of during design and gives best estimates of frequencies of failures for designers and safety analysts to use in treating the new International Thermonuclear Experimental Reactor (ITER) fusion design or other fusion designs. Providing representative vacuum accident events should help safety personnel select initiating events for safety and risk work. Estimates of the frequencies of these events are calculated and also quoted from the literature.

Some definitions are important for this report. The first is leak rate, typically given in throughput units, Torr-liters/second, or Pascal- $\mathrm{m}^{3} / \mathrm{second}$. The leak rate is the quantity of gas (air) in pressure-volume units flowing per unit time into the system of interest. $1-1,1-2$ Once the temperature and gas species are known, the throughput units can be converted to mass flow units, 
such as grams/s. Obviously, the lower the throughput leak rate, the better for the system, since this is a lower mass of foreign material in the system, and pump energy must be expended to remove mass from the system. Often, as happens with other types of engineering systems, leaks are defined on the basis of the ability to measure them. For example, if an ion vacuum gauge is used, then only leak rates above a small value (perhaps values on the order of $10^{-10} \mathrm{~Pa}-\mathrm{m} / \mathrm{s}$ ) are noted. The sizes of leaks, such as 'small' and 'large' will be set on the basis of the capacity of the pumps available to handle the gas loads, just as water system leak sizes are typically set by the ability of the makeup systems to replenish the leakage water. Generally, for fusion experiments $1 \mathrm{E}-05 \mathrm{~Pa}-\mathrm{m}^{3} / \mathrm{s}$ throughput leaks are thought to be large leaks that require system shutdown and leak detection.

Two types of nomenclature for leaks are generally used when discussing vacuum systems: virtual and real leaks. Virtual leaks are not breaches of the vacuum system to the surrounding environment, but rather are the diffusion or evolution of some material from within the vacuum system. A virtual leak could be air leaking from its entrapment within a weld seam or out from the threads of a threaded connection. A subset of virtual leaks are foreign materials in the vacuum system, such as water vapor from atmospheric humidity coming off of the interior walls of the vacuum system, oil evaporating from fingerprints or pump oil contamination within the system, and outgassing from plastic, rubber (elastomer), ceramic seals, or from any number of other foreign materials in the system. Virtual leaks can be as much a source of inconvenience and frustration as real leaks, but generally only good design practices and prudent material choices can preclude virtual leaks. Real leaks are vacuum system breaches, however small, to the surrounding environment. Real leaks might arise from poor seal contact on a flange, foreign material on a seal, a flawed or broken seal, loose flange bolts, a cracked weld (or braze or solder joint) or bellows, a cracked window, etc. This distinction is very important because it dictates the means to remedy the leak problem. Virtual leaks can be treated by good system design (no small 'pockets' in the system that hold air for slow evolution, good weld design, etc.), in-vessel cleanliness practices assiduously followed by construction and maintenance personnel, and system bakeout at high temperatures (perhaps 150 to $300^{\circ} \mathrm{C}$ ) to rapidly (that is, in hours or a day rather than slow evolution over weeks or months) drive water vapor and other gases off the walls for capture by vacuum pumps. Conversely, real leaks can be located with leak detectors and fixed by system maintenance, such as component or seal replacement, by tightening flange bolts, or perhaps placing a temporary guard vacuum over the leak location. The remainder of this report deals with real leaks rather than virtual leaks.

This report is structured to first discuss vacuum system operating experiences from existing fusion experiments, particle accelerators, space simulation chambers, and any other large scale uses of vacuum equipment (vacuum manufacturing, etc.). These experiences are used to form lists of historical-basis accident initiating events. Then safety concerns are discussed, followed by component failure rate estimates and finally, a chapter on postulated initiating events and their frequency estimates. 


\section{Chapter 1 References}

1-1. A. Roth, Yacuum Technology, North-Holland Publishers, Amsterdam, Second Edition, 1982 , page 440.

1-2. M. H. Hablanian, High-Vacuum Technology, A Practical Guide, Marcel Dekker, Inc., New York, 1990, page 41 . 


\section{VACUUM SYSTEM OPERATING EXPERIENCES}

\subsection{Introduction}

This chapter discusses vacuum system experience for fusion facilities, particle accelerators, space simulation chambers, and other facilities that use large vacuum systems (larger than laboratory bench top scale equipment). These experiences have all been found in the published literature or from interviewing experts. Each of the facilities is characterized as well as possible for their given level of published information and resources available for report preparation. Citing these parameters should help determine the similarity of these experiences to future fusion facilities.

\subsection{Fusion Facilities}

Magnetic fusion facility experiences are discussed first, since they are most similar to the proposed International Thermonuclear Experimental Reactor (ITER) and other next generation experiments, such as the U.S. Tokamak Physics Experiment. Several of the large fusion experiments have outlined their vacuum system experiences in various reports, and in papers at conferences and workshops. These experiences are discussed below, for each machine, together with machine parameters to assist the reader in interpreting these experiences.

Tokamak Fusion Test Reactor (TFTR). The TFTR experiment at the Princeton Plasma Physics Laboratory in New Jersey began operation in December, 1982. 2-1 This experiment has operated for over 10 years. The TFTR vessel and ducts enclose about $85.6 \mathrm{~m}^{3}$. TFTR maintains a pressure of about 7E-07 $\mathrm{Pa}$ by using 8 turb spumps, 2 cryopumps, and cryopanels. The vacuum system leak rate is about $3 \mathrm{E}-06 \mathrm{~Pa}-\mathrm{m}^{3} / \mathrm{s}$. The TFTR vacuum system is described in reference $2-2$. Initial operating experience in the first twelve months uncovered some major operational problems. Two of the 14 torus bellows had significant leaks from undetermined causes, all of the 41 high vacuum valves to the vacuum pumping system had significant internal seal leaks and bellows failures, and one of the $12.7 \mathrm{~mm}$ thick neck flanges had significant leaking from through cracking, attributed to flawed material. ${ }^{2-2}$ These problems were all corrected quickly, with a combination of component replacement, patching, and other solutions. Now, the TFTR vacuum system is only a small contributor to overall machine downtime. Magnets and computer systems are the major contributors to downtime.

Princeton has also been the source of several widely-repeated stories of vacuum systems. The two most well-known stories are about a lunch left inside a vacuum chamber, and researchers finding an animal (a mouse, a rat, or a cat, depending on where one has heard the tale) inside the vacuum chamber. In a conversation with Dr. G. D. Martin, a PPPL researcher, the origins of these stories were uncovered. 2-3 The lunch bag left in a machine is an apocryphal story, likely preceding the Princeton Large Torus experiment from the 1970's. Perhaps it did actually happen decades ago, when the machines were small and there were few procedures. The mouse story occurred as part of the stellerator project in the mid-1950's. When a glass u-bend fitting on the 
stellarator had cracked, a new one was obtained from the storage room. The new glass fitting had a small, dead mouse in it. The mouse was discarded and the glass u-bend was thoroughly cleaned, then installed on the stellerator. The mouse was never inside the machine.

PPPL workers have inadvertently left tools, booties, a latex glove, and loose parts (screws, etc.) inside the various fusion experiments. As the experiments grew large enough to allow persons to enter, more items began to be left behind when the vacuum vessel was closed for pump down. Also, the larger the vessel, the more difficult it is to survey for loose parts. Any metallic parts can create problems when the magnetic field is energized. The Princeton Large Torus suffered a rapid pressurization accident in September 1979 when a wrench, caught in the fringe magnetic field, struck and broke a $0.3 \mathrm{~m}$ diameter window. PPPL has also learned several practical vacuum lessons, which Dr. Martin shared with me. Always check to verify if a flange is just being used as a dust cover; that is, do the flanges have proper gaskets in place and are the flange bolts properly tightened? Always verify the positions of valves to avoid pumping down only the volume in the vacuum duct between the pump and its isolation valve. Always check to verify that a helium gas bottle is connected to the helium leak detector, not an argon bottle (in the US and some other countries, all inert gas bottles have the same fitting, so mixing different bottles is possible). Also, Dr. Martin suggests that it takes on the order of several years to become truly proficient at leak testing, and every time new people are brought into a project, some of the same mistakes are repeated. $2-3$

TFTR researchers have also discussed the cleanliness of the TFTR vacuum vessel and vacuum system. Over an operating campaign, several kilograms of dust can be created, and this dust can get into vacuum valves and other components, causing a valve seat leakage problem. $2-4$ This will probably continue to be a problem for future experiments, depending on first wall design. TFTR solutions to date are using gate valves equipped with rings to guard the seat areas and providing passages for the material to settle out. The settling passages also tend to retain the dusts during "up-to-air" (increasing vacuum system pressure to atmospheric pressure) events, which helps to protect the machine. Remote maintenance for dust contaminated vacuum components has also been considered for next generation devices. ${ }^{2-5}$

Joint European Torus (JET). The JET experiment near Culham Laboratory in the United Kingdom initially operated in June 1983. JET is about $200 \mathrm{~m}^{3}$ in volume, and keeps a base pressure of about $1 \mathrm{E}-04 \mathrm{~Pa}$ by using 4 turbopumps. The overall vacuum system leak rate is about $1 \mathrm{E}-05 \mathrm{~Pa}-\mathrm{m} 3 / \mathrm{s}$. The vacuum system is described in references $2-6$ and $2-7$. The double-walled JET vessel is divided into octants, each having about $1 \mathrm{~km}$ of welding and having a design leak rate of $1 \mathrm{E}-07 \mathrm{~Pa}-\mathrm{m}^{3} / \mathrm{s}$. When initially tested after construction, on average one leak per octant was found, ranging from $1 \mathrm{E}-06$ to $1 \mathrm{E}-04 \mathrm{~Pa}-\mathrm{m}^{3} / \mathrm{s}$. These leaks were found and repaired.

Over its lifetime, JET has reported that leaks and other vacuum-related delays have caused more than $10 \%$ of the operation time delay and $2.5 \%$ of the operation time loss. In a good discussion of vacuum problems at JET,2-8 most of the routine vacuum components were evaluated for their performance and leak frequency distribution. Optical windows, electrical feedthroughs, 
bellows, flanges, valves, and vacuum gauges have all presented some level of leakage problem over JET life. In general, JET welds were found to be more reliable (leaktight) than seals, something also true for high pressure water systems. Table 2-1 is a reproduction taken from reference $2-8$, showing the number of vacuum component types and the percentage of those components that leaked in assembly or in operation: The valves evaluated in Table 2-1 include those valves that seal portions of the vacuum system from other portions (not just between vacuum and air). The leakage value of $70.2 \%$ includes leaks across the seats of those valves, but most of those leaks do not hamper machine operation. Later in this chapter, Table 2-1 will be compared to a similar table from a particle accelerator facility. The JET experiment runs well; Table 2-1 simply illustrates how difficult it is to operate large, clean vacuum systems.

The JET discussion of vacuum problems also contains cause and remedy information. Flange leaks were mainly caused by damaged (scratches, dents) seals, uneven heating of the flanges, reuse of seals, and debris intrusion. Valve leaks were most often caused by debris getting lodged in the valve seat, and also by improper, out of sequence operation of the valves. Optical windows of quartz and sapphire have failed due to water impingement with resultant thermal stresses (JET windows normally operate at $250^{\circ} \mathrm{C}$ ), and due to coating debonding from the face of the glass. Water leaks from water cooling lines for the limiters have occurred because of bellows breaches due to excess vibration and weld failures from disruption-induced stresses and vibration. Some of the bellows under high gas or water throughput have failed from excess vibration in a matter of a few days. Bellows failures at JET have been the single largest cause of vacuum system operational delays. There have been problems with electrical penetrations as well. JET designers realized that these would always leak to some extent, and guard vacuums (that is, secondary enclosures pumped with roughing pumps to some low pressure, perhaps 1 to $100 \mathrm{~Pa}$ or so) cause unexpected problems. In the pressure range of 100 to $1 \mathrm{~Pa}$ of air, a voltage of $150 \mathrm{~V}$ can permit an electrical discharge in the air that damages the electrical conductor in the feedthrough. Two solutions have been used at JET - pumping down to $1 \mathrm{E}-03 \mathrm{~Pa}$, or backfilling with a noble gas at 0.5 to 1 atmosphere pressure to provide more resistance to breakdown. $2-8$

Penning vacuum gauges rely on a small permanent magnet to enhance ionizations, and JET's strong magnetic field for plasma confinement caused many Penning gauge magnets to shift position, damaging the gauge's electrical feedthrough (ceramic insulator). Pirani gauges were found to be very prone to mechanical damage, which caused several leaks. $2-8$ Future machines might not experience the mechanical problem, since maintenance would be performed remotely and the gauges could be placed away from maintenance pathways. Shielding from magnet fields will be necessary for future uses of Penning type gauges.

As well as losing integrity (allowing admission of air), some JET in-vessel components have leaked water into the machine. This was briefly discussed above, and can be important to vacuum chamber safety if the water coolant reacts with hot armor tiles to form hydrogen and oxides. Radioactive materials embedded in the first few microns of the tiles would be released during such reactions (tritium, activated dusts) at least locally. The hydrogen generation issue is a safety concern for future experiments. These issues are discussed later in this report. In one event at 
JET, a large amount of water $\left(0.5 \mathrm{~m}^{3}\right)$ flooded the vessel. $2-9$ However, much smaller amounts of water could liberate enough hydrogen to present a potential hydrogen explosion concern; on the order of ten or more liters. Of course, air would have to be admitted as well to result in a deflagration or detonation, so a very tight vacuum system and vessel would help to mitigate a water leak/tile reaction event. Overpressure events must be tolerated by robust design or somehow mitigated by pressure relief; if not, then diagnostic ducts might fail and allow admission of air. Vacuum windows are reputed to not be able to take much more than 1 atmosphere differential pressure; greater differences lead to fracture. JET experience shows that water impingement on hot vacuum windows causes thermal stress-induced fracture, which could lead to air ingress without a large internal overpressure in the vacuum vessel. Ignitors for the generated hydrogen and ingress air could be a vacuum gauge filament (such as that used in a Bayard Alpert Gauge), hot wall tiles, a hot Langmuir probe tip, or perhaps just the static slectricity generated by flowing gas as the vacuum system pressure equalizes.

Table 2-1. Leak percentage distribution by component type in JET

Component Type

Bolted flanges

$V$-band flanges

Lip weld

Butt weld

Fillet weld

Electron beam weld

ConFlat flanges

Windows

Edge welded bellows

Hydroformed bellows

Feedthroughs and gauges

Valves
Number installed

185

137

114

375

1235

48

115

41

75

273

196

57

\section{Percent leakage}

18.9

30.7

13.2

0.8

2.8

10.4

2.6

34.0

13.3

5.5

7.7

Japan Torus-60 (JT-60). JT-60, at the Naka Fusion Research Establishment in Japan, began operation in April 1985. The JT-60 experiment had a $160 \mathrm{~m}^{3}$ vacuum chamber, and its base pressure is about $7 \mathrm{E}-07 \mathrm{~Pa}$, with a leak rate of about $7 \mathrm{E}-08 \mathrm{~Pa}-\mathrm{m}^{3} / \mathrm{s} .2-10$ The JT-60U (U meaning upgrade) has a double walled Inconel vessel, like the JET, DIII-D, and Tore Supra experiments. JT-60U uses turbopumps and getter pumps for its vacuum system. The JT-60U is 
described in reference 2-11. Between July 1986 and October 1987, the original JT-60 device experienced 78 vacuum leaks. These leaks occurred in metal o-ring seals (64.1\%), copper gasket seals $(12.8 \%)$, gate valve bonnets $(11.5 \%)$, gate valve disk seals $(2.6 \%)$, other places $(3.8 \%)$, and unknown (5.1\%). The predominant cause was electromagnetic forces from plasma disruptions (66.7\% of leaks), followed by improper torque-down of components with $17.9 \%$ of the leaks. Misassembly (2.6\%), thermal stresses (3.8\%), bad manufacturing (2.6\%), and "other" $(6.4 \%)$ made up the remainder of the leak causes. $2-10$

Russian superconducting tokamak experiment (T-15). The T-15 experiment is located at the Kurchatov Institute of Atomic Energy, near Moscow. T-15 initially operated with low power pulses in December 1988. 2-12 The T-15 vacuum system is pumped by turbopumps for a base pressure of about $8 \mathrm{E}-05 \mathrm{~Pa}$ and has a typical throughput leak rate of about 7E-05 Pa-m3/s. 2-13 Apparently, turbopumps are the preferred type of pump for existing fusion experiments. Turbopumps are noted for their wide rar:ze of pumping pressures, cleanliness, rapid on-line time, and low maintenance requirements. Their only drawbacks are susceptibility to vibration, possibly radiation, and eddy current heating of the rotor. $2-14$

Other fusion experiment experiences. Experiences from several other fusion experiments have been collected to point out the types of possible faults that can occur. ${ }^{2-15}$ The ranges of faults discussed covers many types of faults: a torus interface valve was inadvertently opened to the atmosphere; in September 1979, the Princeton Large Torus had a wrench, accelerated by the magnetic field, strike and implode an unused vacuum window while the machine was under vacuum; a diagnostic shifting in the magnetic field sheared its line to the vacuum vessel; a retractable diagnostic ran past its stop and tore open its vacuum bellows; diagnostic breaches allowing air inleakage; leaky welds; and bellows failures that allow air ingress. Other leak-prone components for fusion vessels have been defined from past experiences: field welds, bellows, and

seals. 2-16 Other noted fusion experiments, such as the Tore Supra experiment at Cadarache, France, which began operation in April 1988, have not published many vacuum experiences for comparison here.

\subsection{Accelerator Facilities}

Several of the large accelerators around the world, including the facilities at the Center for European Nuclear Research (CERN) in Geneva, Switzerland and the Fermi National Accelerator Laboratory (FNAL) in Batavia, Illinois, publish some of their operating experiences. Since accelerators typically require pressures of perhaps $1 \mathrm{E}-06$ to $1 \mathrm{E}-09 \mathrm{~Pa}$, these experiences can be useful to fusion researchers. One physics researcher for the CERN Intersecting Storage Rings (ISR) experiment, a $2 \mathrm{~km}$-circumference experiment, gave this insight: "The frequency of occurrence of small leaks is reasonably low; it constitutes a nuisance but as yet no more than a slight headache." $2-17$

The ISR experiment uses aluminum for the vacuum chamber, and maintains a pressure between 1E-08 and 1E-09 Pa. Typical of large vacuum systems, ISR researchers have reported 
leaks in vacuum flanges (seal leakage) that were quickly sealed by varnishing the exterior of the flange. The varnish-for-leakproofing seems to be a traditional remedy, but is not recommended for use on any fusion system. Varnish is an oil-based paint substance that sets into a hard, thin film. If varnish was drawn into the vacuum system through the leak location before the varnish hardens, it could pervade the fusion system, leading to virtual leaks as the hydrocarbon chains in the varnish broke down in the vacuum environment. Also, since fusion systems are baked out much more frequently (fusion systems have brief bakeouts weekly, long bakeouts occur perhaps monthly or quarterly; as opposed to yearly bakeouts at accelerators) and often at higher temperatures than accelerator systems, the varnish would not stand up under the thermal stress. Still, varnishing a vacuum flange is, in principle, similar to "furmaniting" a leaky water system flange. Furmaniting is a maintenance process where a hot fluid rubber compound (called furmanite) is injected around the edges of a leaky water flange or valve body, filling the volume between the halves of the flanges. The Furmanite rubber dries and hardens, thereby plugging the leak until the seal can be repacked in next maintenance session. Fusion systems cannot use temporary fixes such as varnishing leaks or other furmaniting processes. A better approach for fusion would be to establish guard vacuums over leak locations until a maintenance session can solve the problem.

The ISR has also experienced 'pressure bumps' of unknown origin. Some sections of the ISR accelerator have experienced localized pressure increases of up to $1,333 \mathrm{~Pa}$. Since accelerators are generally small diameter (less than $1 \mathrm{~m}$ ) and very long circumference (many $\mathrm{km}$ ), the conductance is low and pressure increases can be somewhat localized. The pressure spikes cause loss of the accelerator beam, just as accidental air or water ingress in a fusion reactor would cause a plasma disruption. The LEP pressure bumps might have been large virtual leaks, but the staff did not know the exact cause. Other pressure bursts have been attributed to oil leakage and vaporization from hot oil diffusion pumps, $2-18$ but that is not the case for the ISR.

The Large Electron Positron (LEP) collider at CERN also has some interesting vacuum experiences. 2-19 The LEP staff has documented their initial leakage experiences. These data are recreated in Table 2-2. The LEP is a stainless steel and aluminum chamber, $27 \mathrm{~km}$ in circumference, with an expected 20-year lifetime. With these facts in mind, the information in Table 2-2 can be considered as typical initial operating experience for a large vacuum system. The failure ratio results are positive, since they are all less than $1 \%$. Fusion systems would use many fewer components than the LEP, which should reduce the number of expected leaks.

The flanges cited in the table are all metal to resist radiation levels, baking at $150^{\circ} \mathrm{C}$, and leaks in excess of 3E-11 Pa-m3/s. The larger flanges in Table 2-2 are aluminum (Al) to stainless steel connections, with aluminum alloy 'diamond' cross section metal seals. All of the Kovar (Unified Numbering System K94610, an iron, nickel-cobalt alloy; Kovar is well known for its ease of joining to ceramics and glass $2-20$ ) electrical feedthroughs were replaced by stainless steel and a corrosion resistant nickel-silver ceramic. This was done to reduce any possible corrosion in the LEP tunnel environment. $2-21$ 
For the LEP components that had to be rebaked to meet vacuum criteria (18\% or 358 aluminum chamber units), about a third of them had mechanical failures ( 74 had weld leaks; there were also feedthrough leaks, demountable joint leaks, measuring equipment feedthrough leaks, etc.), and two-thirds had virtual leaks, mainly argon gas evolution from the seams of inert gas welds. The LEP team thought that the vacuum performance was excellent, considering the thousands of components tested and the accelerator tunnel conditions: (a) the tunnel had strong drafts from the ventilators that hanpered leak detection, (b) dust from new cement (construction work) and humidity combined to make corrosive agents, (c) ambient temperatures as low as $5^{\circ} \mathrm{C}$ hampered efforts, and (d) several kilometers distance between tunnel access points made the work tedious. $2-21$

The researchers at the LEP noted that using varnish to seal large leaks, those on the order of 1E-07 $\mathrm{Pa}-\mathrm{m}^{3} / \mathrm{s}$, could cause varnish ingress into the vacuum system, leading to unacceptable system contamination. They would try to stop such leaks in other, more traditional ways, including tightening the flanges, dressing the knife edges, changing the metal seals on the flanges, etc. $2-21$

Table 2-2. Leak Statistics for the Aluminum Portion of the Large Electron Positron Collider, following initial installation and following initial 24 hour bakeout

\section{Component and Number of components}

$225 \mathrm{~mm}$ Al-steel flanges; 5,569

$113 \mathrm{~mm} \mathrm{Al-Al} \mathrm{flanges;} \mathrm{7,916}$

Bellows; 3,122

Beam position

ceramic feedthroughs; 2,168

Getter pump feedthroughs; 3,942

Ion pump feedthroughs; 1,908

Aluminum chamber welds; 2,721

\section{Leaks after installation Leaks after bakeout}

$\begin{array}{rr}16,0.3 \% & 3,0.06 \% \\ 14,0.2 \% & 12,0.2 \% \\ 22,0.8 \% & 3,0.1 \% \\ 12,0.7 \% & 5,0.3 \% \\ 17,0.5 \% & 7,0.2 \% \\ 5,0.4 \% & 7,0.5 \% \\ 0,0 \% & 10,0.04 \%\end{array}$

Note: Leak rates are greater than $3 \mathrm{E}-11 \mathrm{~Pa}-\mathrm{m}^{3} / \mathrm{s}$ at installation and $3 \mathrm{E}-12 \mathrm{~Pa}-\mathrm{m}^{3} / \mathrm{s}$ after bakeout, but not much greater in most of ine leaks listed here.

Bakeout was a 150 or $300^{\circ} \mathrm{C}$ (lower temperature for aluminum (Al) parts, higher temperature for stainless steel interfaces).

Comparing Tables 2-1 and 2-2 provides some interesting insights. While the LEP has many more components than JET, it has uniformly lower leakage percentages than JET. JET has only 3\% of the number of LEP flanges, only $65 \%$ the number of welds, $11 \%$ of the number of bellows, and only $2.5 \%$ of the number of feedthroughs. However, JET has had almost 20 times the number of leaks in flanges, more than 400 times the number of weld leaks, 20 times the number of bellows leaks, and 5 times the number of feedthrough leaks. Possible explanations for these results are that 
the LEP uses many aluminum parts, these parts are baked out at about half the temperature that JET is baked out, and LEP does not operate at elevated temperatures like JET, so the LEP has less thermal stress. JET also experiences more vibrations and other mechanical stresses due to plasma disruptions. The components on JET are typically larger than on LEP, so issues of proper flange alignment and tightening, and other installation and maintenance issues can vary between the two machines. While the JET estimates are higher than LEP estimates, other fusion experiments have leakage experiences that are closer to the LEP results. For example, the Axial Symmetric Divertor Experiment (ASDEX), which operated between February 1980 and August 1990, showed that there were only a few vacuum leaks with hundreds of flanges. Only two hours of machine downtime for the decade were attributed to vacuum problems. ${ }^{2-22}$ Still, it is possible that applying accelerator vacuum component reliability results to fusion component results would overpredict fusion reliability, so JET-size machine fusion estimates will be used whenever possible to extrapolate to future fusion machines. Since JET useful life failure experience gives higher values than LEP beginning of life experience, increases to apply accelerator component failure rates to fusion components are prudent. Vacuum component failure rates are discussed in Chapter 5.

The Lanzhou cyclotron in China has had several experiences as well. This vacuum chamber has a design pressure of $6.5 \mathrm{E}-06 \mathrm{~Pa}$ (5E-08 Torr). On initial (commissioning) pumpdown, after one hour of rough vacuum pumping, the Lanzhou researchers experienced leakage from aluminum gasketed steel flanges that had "slackened" screws, perhaps from material relaxation or personnel oversight. The flanges were tightened. After another 100 hours of high vacuum pumping with cryopumps and turbopumps, there were still some small leaks present. The Lanzhou researchers also noted that since there were no valves to isolate the cryopumps from the vacuum chamber, they avoided using any fragile components in the vacuum boundary (bellows, etc.) so that any accidental air ingress was eliminated; therefore, the pumps would not be damaged. $2-23$

The Stanford Linear Accelerator Center's positron electron accelerator ring (SPEAR) has had several interesting experiences. In one event, a braze failure at a ceramic to stainless steel interface caused the experiment to increase "up to air" pressure. After repairs, the chamber could not be restored to high vacuum, until an extensive 4-day bakeout session was conducted. 2-24

The FermiLab particle accelerator, the Tevatron, uses small turbopumps $(160 \mathrm{~V} / \mathrm{s})$ at 210 cryostat vacuum fixed position stations and $\mathbf{4 8}$ mobile beam tube pumping carts throughout the facility. The flexhoses between the turbopump and its backing pump are stuffed with copper pot scrubbers to retard oil migration, and these hoses are changed out with each pump oil change (yearly). The turbopump's forepumps are run at 33\% speed reduction from rated values to allow these mechanical pumps to run at $10^{\circ} \mathrm{C}$ cooler temperature, thus increasing their useful life. Parts installed on the Tevatron are tested to a leak rate of $2 \mathrm{E}-11 \mathrm{~Pa}-\mathrm{m}^{3} / \mathrm{s}$, and researchers estimate that only $5 \%$ of installed parts develop leaks within the body of the device. Bellows faults are the worst problem for vacuum integrity, which is similar to JET results discussed earlier. Tevatron seals that leak are carefully rubbed down with number 600 polishing grit to remove any scratches, which are the most common reason for seal leaks. $2-25$ Scratches are also the main cause of fusion flange seal leaks. ${ }^{2-26,2-27}$ For the Tevatron, out of 256 seals inspected, 48 needed replacement 
on a first test, 10 after a second test, and only 1 after a third test. The Tevatron also has had some small problems with helium and nitrogen leaks that can cause up to a few tenths of a percent $(0.2$ to $0.3 \%$ ) of the seals to leak helium into the beam tube. The Tevatron personnel have not found any evidence that multiple thermal cycles cause increases in leak rates for these components. They have had one event where a faulty bellows leaked, causing a warmup of an entire sector of the machine. $2-25$

The Daresbury facility in the United Kingdom has also experienced some interesting faults. On their calibration vacuum system, high speed (43,000 rev/minute) turbomolecular pumps are used. On one occasion, while the turbopump was operating, an internal seal in a rotary pump failed, allowing oil to enter parts of the vacuum system. The isolation valve above the turbopump received the appropriate sensor signal when the turbopump rotor began to slow down from the oil load, and the valve isolated the pump. Upon recovery from that event, an air leak was encountered from a 'closed' valve. While the valve seat was being tightened to repair the leak, the sapphire cracked, which resulted in venting the entire chamber to the atmosphere. The interlock system again functioned correctly, closing appropriate valves so that the pumps were isolated. Another problem that they have faced was ion pumps continually tripping the residual current circuit breakers, so the staff limited the operating temperature of the ion pumps to only $330^{\circ} \mathrm{C} .2-28$

\subsection{Space simulation chambers and other applications}

Space simulation chambers must be designed for more than just maintaining pressure of the given altitude above the earth. Ion bombardment, electromagnetic radiation from the sun, collisions with stray particles in orbit, and other factors are also taken into account.2-29 At the Skeats laboratory in the US, a vacuum-related fatality occurred at a missile nose cone testing chamber when a vacuum window imploded from either age or inadvertent impact. This event is discussed more fully in Chapter 4.

The European Space Tribology Laboratory in the United Kingdom has reported that vacuum equipment reliability is very important to performing good tests. This facility operates at about 1.3E-05 $\mathrm{Pa}$, and performs some very delicate measurements. Therefore, vibration isolation is very important as well as cleanliness. Some cryopump faults there disrupted the tests and endangered the item under test. Oil got into the cryogenic helium from the compressor, and caused additional problems. In contrast, the turbopumps performed very well. In one instance, a turbopump was found destroyed due to vane fatigue after only 6000 hours of operation, but there was no system breach, just some pumping port contamination by particles from the vanes and metallic dust residue. Diode ion pumps performed well in an 8 year experiment run. Rotary feedthroughs did not perform well and were a source of constant leakage problems. Hot cathode ion gauges (Bayard-Alpert Gauges) were found to be accurate to within only about $\pm 30 \%$. $2-30$

Experiences with vacuum furnaces in industry, which can operate at $1 \mathrm{E}-03 \mathrm{~Pa}$, indicate that admission of air into the chamber (chambers run at over $1000^{\circ} \mathrm{C}$ ) can create problems because air 
can attack any graphite or refractory metal at high temperatures. ${ }^{2-31}$ This is also a problem for fusion experiments that run at high temperatures.

Table 2-3 gives a summary of the types of vacuum problems discussed in this chapter from the variety of fields reviewed. These events will be addressed throughout this report.

Table 2-3. Summary of vacuum cnisponent faults cited in the literature

Valve internal seal leaks

Bellows leaks

Flange cracking leaks

Personnel leaving foreign materials inside the vacuum vessel

Improperly tighten flanges

Valve positions not verified, causing damage to system

Gas other than helium being supplied to helium leak detectors

Dust intrusion into valve seats and seals causes leaks

Window, electrical feedthrough, weld, bellows, flange, and vacuum gauge leaks

Electrical feedthroughs experiencing electrical discharges in low pressure air

Valve bonnet leaks

Inadvertent opening of valve to atmosphere

Objects in magnet fringe field impacting the torus or shifting position to shear vacuum lines

Diagnostics tearing bellows due to misalignment

Diagnostic window cracks, bloating, or other weaknesses that allow air ingress

Water inleakage from metallurgy faults, bad welds

Intrusion of dust into the vacuum system

Loss of tension in flange bolts, leading to air leaks

Braze failure at ceramic to metal interface, leading to air leaks

Rotary feedthroughs leaking badly 


\section{Chapter 2 References}

2-1. M. D. Machalek, "First Plasma Operation of TFTR," Eusion Technology, 4, September 1983, pages 191-193.

2-2. R. B. Krawchuk et al., "Operational Experience and Initial Performance of the TFTR Vacuum System," Proceedings of the 10th Symposium on Fusion Engineering, Philadelphia, PA, December 5-9, 1983, IEEE catalog number 83CH1916-6, pages 10811087.

2-3. G. D. Martin, PPPL vacuum and cryogenics expert, private conversation, October 14, 1991.

2-4. P. H. LaMarche et al., "Contamination of the Vacuum Pumping Lines of the Tokamak Fusion Test Reactor," Eusion Technology 92. Proceedings of the 17th Symposium on Eusion Technology, Rome, Italy, September 14-18, 1992, pages 1172-1175.

2-5. J. D. Stringer and J. D. Blevins, "Maintenance of Large Gate Valves in Torus Vacuum Pumping Systems," Eusion Technology 92. Proceedings of the 17th Symposium on Fusion Technology, Rome, Italy, September 14-18, 1992, pages 1594-1598.

2-6. M. Huguet et al., "The JET Machine: Design, Construction, and Operation of the Major Systems," Eusion Technology, 11, 1987, pages 43-70.

2-7. K. J. Dietz, "Modifications to the JET Vacuum Vessel as a Result of Plasma Operation," Vacuum, 38, 1988, pages 591-595.

2-8. T. Winkel and J. Orchard, "Leak Evaluation in JET and Its Consequences for Future Fusion Machines," Yacuum, 41, 1990, pages 1988-1991.

2-9. R. Herman, Eusion. The Search for Endless Energy, Cambridge University Press, Cambridge, 1990, page 222.

2-10. M. Shimizu and T. Arai, "Vacuum Technological Experiences of JT-60 Operation," Proceedings of the Japan-U.S. Workshop P-118 on Vacuum Technologies for Fusion Devices, document number IPPJ-T-38, August 1-5, 1988, pages 36-56.

2-11. H. Ninomiya et al., "JT-60 Upgrade Device for Confinement and Steady State Studies," Plasma Devices and Operations, 1, 1990, pages 43-65. For the basic machine description, see M. Ohta et al., "The JT-60 Tokamak Machine," Eusion Engineering_and Design, 5, 1987, pages 27-46. 
2-12. V. S. Strelkov, "ECRH in Low q Plasma in T-10, The First Plasma in T-15," Plasma Physics and Controlled Fusion, 31, 1989, pages 1699-1701.

2-13. L. S. Gurevich et al., "T-15 Vacuum System," Plasma Devices and Operations, 1, 1992 , pages 267-275.

2-14. D. G. Goetz, "Large Turbomolecular Pumps for Fusion Research and High-energy Physics," Vacuum, 32, 1982, pages 703-706.

2-15. L. C. Cadwallader, Steady State Advanced Tokamak Water and Air Ingress Bounding Erequency Estimates, PPPL document number 92-921201-INEL/LADWALLADER-01 for the Tokamak Physics Experiment program, December 1, 1992.

2-16. R. Gallix, "CIT Vacuum Vessel, First Wall, and Divertor Conceptual Design," Proceedings of the U.S.-Japan Workshop P118 on Vacuum Technologies for Fusion Devices, document number IPPJ-T-38, Aug''st 1-5, 1988, page 255.

2-17. E. Jones, "The Operation of the ISR Facility in Relation to the UHV Environment," Vacuum, 22, 1979, pages 299-302.

2-18. R. A. Fluegge and J. E. Huber, "Pressure Bursts in High-Vacuum Systems," Joumal of Vacuum Science and Technology, 8, 1971, pages 419-423.

2-19. LEP Vacuum Group, "LEP Vacuum System: Present Status," Vacuum, 41, 1990, pages 1882-1886.

2-20. A. Roth, Vacuum Technology, second edition, North-Holland, Amsterdam, 1982, pages 370-371.

2-21. J. P. Bacher and N. Hilleret, "Corrosion of Accelerator Vacuum Systems: Risks and Prevention," Yacuum, 41, 1990, pages 1914-1916.

2-22. U. Schneider and the ASDEX Team, "Ten Years of Operating Experience with ASDEX," Eusion Technology 1992. Proceedings of the 17th Symposium on Fusion Technology, Rome, Italy, September 14-18, 1992, pages 742-746.

2-23. Z. Shuxiu, "Vacuum Pumping System for the Lanzhou Cyclotron," Vacuum, 38, 1988, pages 125-127.

2-24. D. Bostic et al., "Vacuum System for the Stanford-LBL Storage Ring (PEP)," IEEE Transactions on Nuclear Science, NS-22, 1975, pages 1540-1543. 
2-25. C. L. Bartelson et al., "The Fermilab Tevatron: Vacuum for a Superconducting Storage Ring," Journal of Vacuum Science and Technology, Al, 1983, pages 187-195.

2-26. G. M. Fuller and J. R. Haines, "Design Considerations for Achieving High Vacuum . Integrity in Fusion Devices," Joumal of Vacuum Science and Technology, A2, 1984, pages 1162-1169.

2-27. R. L. Livesey, "Summary Abstract: Vacuum System Problems of EBT--A Steady-State Fusion Experiment," Joumal of Vacuum Science and Technology, 20, 1982, pages 11881189.

2-28. A. P. James, "The Ultra High Vacuum (uhv) Calibration Facility at Daresbury Laboratory of the Science and Engineering Research Council (SERC)," Yacuum, 37, 1987, pages 343346.

2-29. D. J. Santeler et al., Vacuum Technology and Space Simulation, NASA-SP-105, US National Aeronautics and Space Administration, 1966.

2-30. K. Parker, "Some Experiences of Thermal Vacuum Testing of Spacecraft Mechanisms," Vacuum, 37, 1987, pages 303-307.

2-31. O. Oren, "Experience with Vacuum Furnaces for Industrial Heat Treatment," Vacuum, 21, 1971, pages 331-333. 


\section{VACUUM SYSTEM ACCIDENTS}

\subsection{Introduction}

This chapter contains descriptions of the few actual vacuum system accidents that have occurred at fusion experiments and accidents that have been postulated. Accidents that have occurred have not released any significant amount of radioactive effluents, but for future machines there could be much larger effluent source terms. Data to support analyses and consequence estimation are referenced and discussed.

\subsection{Air inleakage}

As seen in the previous chapter, air or other gases leaking into the vacuum system is the most common problem. The air leaks can occur from any component that does not maintain its integrity. In that sense, all vacuum components are prone to single failures, unless they are redundant (such as multiple vacuum windows in a given port, or multiple, concentric bellows). The leak size is an issue, since some components are known to allow migration of air into the system. For example, ceramic insulators and quartz windows allow a small amount of air outgassing or migration even when fully intact. Small leaks can be handled by the vacuum system pumps. Most vacuum systems need one or more pumps running continually to maintain a given level of vacuum. For the DIII-D experiment (with a base pressure of about $1 \mathrm{E}-06 \mathrm{~Pa}$, and a normal or typical throughput leak rate of about 3E-06 Pa-m $3 / \mathrm{s}$ ) in La Jolla, California, a $1 \mathrm{E}-05 \mathrm{~Pa}-\mathrm{m}^{3} / \mathrm{s}$ leak signifies a reduced efficiency operation state (small leak). A $1 E-04 \mathrm{~Pa}-\mathrm{m}^{3} / \mathrm{s}$ leak rate is a 'stop-and-fix' problem because the air admission would hamper any plasma operations (large leak). ${ }^{3-1}$ Inleakage events in excess of $1 \mathrm{E}-04 \mathrm{~Pa}-\mathrm{m}^{3} / \mathrm{s}$ are classified as very large leaks.

Extreme air inleakage events (called 'up to air' events, meaning quick equilibration of vacuum system and atmospheric pressures) are detrimental for fusion experiments for several reasons. First, the air inleakage would lead to a plasma disruption, if the experiment is operating at the time of the leak. Disruptions are planned for in experiment design, but the intensity of a disruption caused by a large air ingress event could be worse than normal, leading to faster erosion of the protective wall tiles and more tile dust generation. Second, air ingress can bring atmospheric humidity and entrained foreign material into the vacuum system, contaminating the vacuum chamber so that extensive cleaning is required to eliminate outgassing and potential plasma contamination - hours, days, or perhaps even a week of cleaning to make the machine ready for operation again. Third, a breach of the vacuum chamber or system can easily lead to a release of radioactive tritium or activated/contaminated dust, or both. ${ }^{3-2}$ Fourth, large air ingress can threaten the integrity of the vacuum pumps, depending on the type of pumps used. Turbopumps, favored for their cleanliness, quick time to full pumping ability, and their reasonable pumping speed, can experience rotor and hub overstress from aerodynamic friction if too much gas is loaded onto them. This problem was discussed briefly in Chapter 2. 
Turbopumps can have circuits that automatically signal for isolation by closing a valve if the rotor speed suddenly drops below a critical value. Liquid helium cryopumps and cryopanels can experience heatup problems due to the incoming air. Therefore, overpressure protection in the cryopump lines must be provided in case of heatup and/or phase change pressurization. Also, large air ingress can cause all cryopumps to require simultaneous regeneration, which is another operational delay. Air ingress can also threaten vacuum gauge integrity, such as the filaments in Bayard Alpert gauges. These gauges are important for controlling the vacuum pumps and providing operators with information about system status. Another serious concern for air inleakage is the potential for explosion as air mixes with deuterium and tritium that evolve from the cryopumps. $3-3$ Also, air ingress releases varying amounts of tritium from the codeposited layer on the plasma facing components and walls, depending on the surface temperature; at room temperature, perhaps $10 \%$, at $300^{\circ} \mathrm{C}, 100 \%$.3-4 The ingress air could also react with the hot plasma facing components, which would mean the tiles would need replacement. The reaction heat could also drive effluents out of the vacuum system breach location.3-5 Certainly the coolant loss would also be a thermal transient to the wall materials, possibly leading to tile cracking or other damage that also requires tile replacement.

\subsection{Water or Coolant Inleakage}

Water has leaked into the vacuum system of many fusion experiments that use water coolant. Both JET and Tore Supra have had water leaks, some being large. In the Tore Supra event, a copper cooling tube experienced a flow blockage during plasma operation. The tube overheated and then fractured, releasing about 0.5 liter of water into the vacuum vessel. A plasma disruption followed the leak, 3-6 but there was no information about the severity of the disruption relative to typical density-limit disruptions. JET has also reported several small water inleakages from water-cooled equipment, such as the limiter. Those leaks occurred because of tubing material flaws and a few were weldrelated problems. 3-7 JET also had one large water leak event, or rather torus flood event, as described in Chapter 2. Fortunately, the vessel walls were only at about $200^{\circ} \mathrm{C}$ at the time.

The effects of postulated large scale water leakage, generally referred to as a Loss of Coolant Accident (LOCA), into a vacuum system have been studied by several authors. 3-8,3-9 The US Fusion Safety Program has studied the volatility effects of air and steam admission into a hot vessel, with the protective tiles under accident conditions. Several materials, such as steel, carbon, beryllium, and others have been investigated for their response to air and steam ingress events. 3-10 to 3-20

Water ingress can cause window fracture, as noted in Chapter 2 from JET experience, and the water could also damage pumps if it intrudes into the pump casing. Almost any kind of pump would be damaged by water ingress. Turbopumps have blade stress concerns, cryopumps have heatup concerns, ion and sublimation pumps could have 
short circuit and filament damage concerns. None of these pumps could easily be restored to operation after being inundated with a large amount of water.

\subsection{Plasma disruption effects}

The JET experiment suffered a vacuum vessel shift as the result of a plasma disruption in June 1984. The plasma was beginning to disrupt from its own instabilities, and a control error by the vertical plasma positioning system aggravated the disruption. The 2.7 MA plasma was driven 1 meter downward over $20 \mathrm{~ms}$. The result was a force loading of 250 tons (over $2 \mathrm{MN}$ ) 3-21 that moved the over $100,000 \mathrm{~kg}$ vessel $3-22$ down against its supports and then upward by about $10 \mathrm{~mm}$. There were some small permanent vessel deformations. The slamming sound of the vessel moving echoed throughout the JET building. 3-23 Such events must be precluded for future experiments where the plasma carries even more current (the ITER experiment could carry a 24 MA plasma). Such events are a leading reason that a fusion vessel must be structurally strong.

\subsection{Equipment Faults}

Turbopumps are very high speed pumps, turning in excess of 10,000 revolutions per minute (rpm). As with other high speed moving parts, there can be a danger of rotor or hub faults generating missiles. Mr. R. O'Hara of the DIII-D experiment discussed one such event. 3-24 A 5,000 1/s turbopump rotor seized because of poor bearing lubrication while the pump had been running at rated speed of $35,000 \mathrm{rpm}$. The aluminum rotor blades broke and flew up out of the pump inlet, piercing the foreign objects screen. [note: these screens give a small decrease in pumping speed, but are well worth the decrease to keep foreign objects such as screws, weld beads, stray tools, etc., out of the pump] The blade pieces struck the vacuum chamber walls at a tee section of the vacuum duct directly above the turbopump, but there was no damage to the duct walls. The aluminum rotor pieces had insufficient energy to dent, much less penetrate, the stainless steel vacuum duct walls. The space simulation chamber experiences from Chapter 2 and other turbopump experiences also mention rotors flying apart, fortunately without notable effects other than loss of the pump. 3-25 Large air ingress or water ingress events must be considered because they could damage the turbopump rotor or both the rotor and stator by increased forces on the bearings and on the rotor blades. High temperature exposure can cause the rotor blades to warp and fail; turbopumps are generally limited to $120^{\circ} \mathrm{C}$ "line-of-sight" temperatures.

While turbopump rotor breakup is not welcome because of the equipment loss and downtime for replacement, several operating experiences indicate that the event does not directly lead to a breach of the vacuum chamber. However, if the turbopump is not isolated after a rotor breakup, then there could be pressure-driven backstreaming through the secondary mechanical pump aligned to the turbopump exhaust. 3-25 
Cryopumps and cryopanels could fail by leaking cryogen into the vacuum chamber. This event would be difficult to mitigate, since the level of vacuum pressure and the hot chamber walls would cause a cryogen phase change, pressurizing the chamber with cool nitrogen or helium gas. 3-26 For these two cryogens, the gas-to-liquid volume ratios could be over 100 to 1 for low temperatures, and higher as the gases warm to room temperature. If the chamber is small, then it must have rupture disks to protect the system from overpressurization failure. If the pressure is high enough for the rupture disks to open, then the effluent must be routed to an expansion volume (holding tank or other confinement location) since the escaping gas would entrain tritium and activated dusts. If the pump or panel is quickly isolated from the vacuum chamber, then only the pump (or panel) casing will overpressurize, and its rupture disk will relieve to an expansion volume. The amount of radioactive effluent (mainly tritium) would be reduced to only that trapped on the cryogenic surfaces.

\section{Chapter 3 References}

3-1. P. Taylor, DIII-D experimentalist at General Atomics, private conversation, November 12, 1993.

3-2. A. V. Jones and P. Rocco, "Air Ingress Accidents in Tokamaks," Eusion Technology 1988. Proceedings of the 15th Symposium on Fusion Technology, Utrecht, The Netherlands, 19-23 September 1988, pages 1731-1739.

3-3. W. G. Graham et al., "Explosion Source Potential of Neutral-Beam-Source Cryopumps for TFTR," Proceedings of the Third Topical Meeting on the Technology of Controlled Nuclear Fusion, Santa Fe, New Mexico, May 9-11, 1978, CONF-780508, pages 931-934.

3-4. R. A. Causey et al., "Tritium Release from a Codeposited Layer of Carbon and Tritium During Air Exposure," Journal of Vacuum Science and Technology, A7, 1989, pages 1078-1082.

3-5. L. Deleanu et al., "Safety Analysis Related to the Possible Release of Activated Erosion Dust in Fusion Reactors," Eusion Technology 1986. Proceedings of the Eourteenth Symposium on Fusion Technology, Avignon, France, 8-12 September 1986, pages 1329-1334.

3-6. K. J. Dietz et al., "Experience with High Heat Flux Components in Large Tokamaks," Fusion Engineering and Desien, 16, 1991, pages 229-251. 
3-7. M. Huguet, "Assembly, Commissioning, and First Operation of JET," Proceedings of the 10th Symposium on Eusion Engineering, Philadelphia, Pennsylvania, December 5-9, 1983, pages 834-842.

3-8. E. Ebert and J. Raeder, "Synopsis of LOCA, LOFA, and LOVA Accidents for NET/ITER," Eusion Technology 1990. Proceedings of the 16th Symposium on Eusion Technology, London, United Kingdom, 3-7 September 1990, pages 1472 1476.

3-9. F. Andritsos et al., "Loss-of-Vacuum, Loss-of-Coolant, and Loss-of-Flow Accidents Analyses for NET/ITER," Eusion Technology 1990. Proceedings of the 16th Symposium on Fusion Technology, London, United Kingdom, 3-7 September 1990, pages 1477-1481.

3-10. S. P. Henslee, "The Volatility of Vanadium From a Candidate Fusion Reactor Alloy," Transactions of the American Nuclear Society, 46, June 1984, pages 284286.

3-11. R. M. Neilson, Jr., "Volatility of Vanadium from a Candidate Fusion Reactor Alloy," Joumal of Nuclear Materials, 141-143, 1986, pages 607-610.

3-12. S. J. Piet et al., "Oxidation/Volatilization Rates in Air for Candidate Fusion Reactor Blanket Materials, PCA and HT-9," Joumal of Nuclear Materials, 141-143, 1986, pages 24-28.

3-13. S. J. Piet et al., Initial Experimental Investigation of the Elemental Volatility From Steel Alloys for Fusion Safety Application, EGG-FSP-8459, EG\&G Idaho, Inc., April 1989.

3-14. G. R. Smolik et al., "Volatility from Copper and Tungsten Alloys for Fusion Reactor Applications," Proceedings of the Thirteenth Symposium on Fusion Engineering, Knoxville, TN, October 2-6, 1989, pages 670-673.

3-15. G. R. Smolik et al., "Predictions of Radioactive Tungsten Release for Hypothetical ITER Accidents," Eusion Technology, 12, 1991, pages 1398-1402.

3-16. G. R. Smolik et al., "Implications of Beryllium: Steam Interactions in Fusion Reactors," Џoumal of Nuclear Materials, 191-194, 1992, pages 153-157.

3-17. G. R. Smolik, Tungsten Alloy Oxidation Behavior in Air and Steam, EGG-FSP10166, EG\&G Idaho, Inc., March 1992. 
3-18. G. R. Smolik and K. A. McCarthy, Oxidation and Volatilization of a Niobium Alloy, EGG-FSP-10341, EG\&G Idaho, Inc., July 1992.

3-19. G. R. Smolik et al., Reactir of Porous Beryllium in Steam, EGG-FSP-10346, EG\&G Idaho, Inc., July 1992.

3-20. G. R. Smolik et al., "Evaluation of Graphite/Steam Interactions for ITER Accident Scenarios," Eusion Technology, 19, 1991, pages 1342-1348.

3-21. M. Huguet et al., "Present Status and Commissioning Operation of JET," Eusion Technology 1984. Proceedings of the thirteenth symposium on fusion technology, Varese, Italy, 24-28 September 1984, pages 91-103.

3-22. M. Huguet et al., "The JET Machine: Design, Construction, and Operation of the Major Systems," Eusion Technology, 11, 1987, pages 43-70.

3-23. R. Herman, Fusion. The Search for Endless Energy, Cambridge University Press, Cambridge, 1990, page 152.

3-24. R. O'Hara, DIII-D vacuum specialist at General Atomics, private conversation, November 7, 1990.

3-25. B. S. Halliday and B. A. Trickett, "Vacuum Problems on a 5-GeV Electron Synchrotron," Journal of Vacuum Science and Technology, 2, 1972, pages 42-45.

3-26. M. E. P. Wykes, Joint European Torus Safety Analysis Report for the Preliminary Tritium Experiment, MW/ES/047, JET Joint Undertaking, August 7, 1991. 


\section{SAFETY CONCERNS IN VACUUM SYSTEMS}

\subsection{Introduction}

The safety concerns with vacuum systems are numerous. There are mechanical, electrical, chemical, cryogenic, and thermal hazards from the components in the systems, such as flange clearances, purnps (power requirements, oils, possible use of cryogenics), gauges, and bakeout subsystems. 4-1,4-2 As discussed in Chapter 3, the most serious vacuum-related concern for fusion is breaching the vacuum system, since this can lead to a radiation release incident, and it can also cause tokamak downtime. There are several safety concerns regarding system integrity. These are vacuum vessel irradiation/fatigue life, mechanical stresses from thermal expansion/contraction of dissimilar metals, electromagnetic stresses on the vacuum vessel during plasma disruptions, damage by runaway electrons during major disruptions, magnetic field effects on the vacuum vessel and vacuum system, fire and explosion hazards in the vacuum pumps, and system corrosion problems. These concerns are briefly addressed in this chapter. Several important personnel safety concerns are also included at the end of the chapter.

As discussed in Chapter 2, events that cause a system breach are possible for fusion experiment vacuum systems. These systems are the primary containment for radioactive tritium, (both the tritium produced in deuterium reactions, and tritium directly used as a fuel) and activated tokamak materials ("tokamakium" dusts). U.S. Department of Energy Order $6430.1 A^{4-3}$ states that the fusion vacuum vessel is a primary confinement system and must withstand any possible hydrogen explosion (such as that due to air inleakage with cryopump hydrogen outgassing or because of air mixing with hydrogen from steam-plasma facing component interactions). Prudent design indicates that source materials for explosion should be eliminated, ignition sources should be eliminated, and that the system should also be robust enough to withstand explosions if it is conceivable that explosive conditions could still occur.4-4 TFTR satisfied this requirement by diluting the hydrogen isotope streams with helium and having a cleanup system for the vacuum vessel, so that any air leakage is inward rather than outward upon vessel breach. Therefore, the confinement function, if not actual confinement, is preserved. This issue of primary confinement must be addressed for future fusion designs.

\subsection{Vacuum Vessel Irradiation}

Another air inleakage concern is deterioration of the fusion vacuum vessel with age. Fusion vessels are typically very well constructed devices, designed to mechanical engineering code standards for buckling and to withstand plasma disruption forces, but the many ports and penetrations require windows or other covers that are not as structurally strong as the walls. The vessel walls also withstand harsh environments more easily than the windows and other penetration seals. A radiation damage assessment of the Joint European Torus (JET) vacuum vessel using Inconel coupons to predict the damage to the vessel has shown that the JET vessel can withstand another 5 years of vessel operation without failure. ${ }^{4-5}$ The fatigue life to date has been only a few percent of the calculated fatigue life of the Inconel vessel. Other fusion vacuum vessels 
can be expected to behave in a similar manner, unless the fluences increase dramatically, in which case irradiation will limit vessel lifetime.

Vacuum windows for fusion diagnostics are more susceptible to radiation damage than the vessel walls. There are several kinds of windows in use, either quartz or sapphire for optical diagnostics, and thin metals for neutron collection. The quartz windows have been studied for radiation damage, both browning and embrittlement. 4-6 Prediction techniques have been developed to estimate the lifetime of these windows.47,4-8

The TRISTAN accelerator vacuum system in Japan is constructed of aluminum, similar to many accelerators. Aluminum can accommodate the external pressure forces, and it is less expensive and more easily machined than Inconel or stainless steel. Strength, fabricability, and cost are major factors for such large (kilometers in diameter) systems. Radiation damage at accelerators is not a major safety concern, but radiation can create corrosive products from the mixture of inleakage air and outgassed products from seals. 4-9,4-10 Fusion systems should be able to avoid this concern if all metal gaskets are used rather than any sort of elastomer seal.

\subsection{Mechanical Vibrations and Stresses}

The choice of pumps may allow vibrations to be transmitted to the vacuum vessel and system. Large turbomolecular pumps and their backing pumps can transmit vibrations on the order of $60 \mathrm{~Hz}$. The backing pumps are vibratory in nature (either rotary vane pumps, piston pumps, etc.), and the turbopump itself may vibrate because of rotor imbalance. Using bellows connections will reduce the vibration, but will introduce a potentially leaky component into the vacuum system.4-11 However, there are other, larger sources of vibration in the vacuum system. The magnets can create vibrations in the vessel and ducts, as well as the plasma. Mechanical stresses must be accounted for in system design.

\subsection{Electromagnetic Stresses}

Vacuum vessels and ductwork are typically made from stainless steel or Inconel. Magnetic fields from the toroidal magnets might be on the order of 5 Tesla at the center of the plasma, higher at the vacuum vessel walls. Large forces can be generated in the vacuum vessel during off-normal events, such as partial cooling interruptions, or plasma disruptions. Adequate resistance to plasma disruptions is a main design criteria for vacuum systems. ${ }^{4-12,4-13}$ Disruptions can load meganewton sized electromagnetic stresses on the vessel.

\subsection{Runaway Electrons}

Existing fusion experiments have suffered damage from runaway electrons. Such electrons can be energetic enough (up to the $100 \mathrm{MeV}$ range) to pierce protective tiles and damage the vessel walls or coolant piping, even breach coolant piping. These electrons have already damaged walls and limiters of existing fusion machines.4-14,4-15 Some runaway electron modeling has been 
performed, 4-16,4-17 and this modeling is very important for safety since coolant leaks pose a safety concern. These electrons are not accounted for in any existing component failure rate estimates, since prediction of their generation and effects is highly speculative. When more is known about these electrons, then they can be better accounted for in reliability and safety analyses.

\subsection{Magnetic Forces}

The magnetic fields generate forces in piping and ducting on the vacuum vessel, as well as in the vessel itself.4-18 Generally, these forces are much lower than those of the high pressure fluids within the piping. Still, proper reinforcing is essential for all piping and vacuum ducting. Eddy currents, their forces and torques generated by the magnetic fields are also under investigation. 4-19 Other problems with magnetic fields are their effects on vacuum components. Metallic turbopump rotors, usually aluminum, are susceptible to eddy current heating and consequent swelling. 4-20 Such swelling from heatup can threaten the close tolerances in the pump. Ceramic rotors have been investigated for this reason. 4-21 Turbopumps have been investigated for magnetic bearings, but shielding from the larger magnetic fields must be very good, or rotor imbalance could result. Bayard-Alpert ion gauges have been investigated for their accuracy in small magnetic fields (5 gauss to 60 gauss; 1 gauss $=1 \mathrm{E}-04$ Tesla).4-22 The gauge was definitely affected by the magnetic field. The authors recommended placing the gauge to take advantage of the field direction. The ions created in the gauge will follow the field lines, just as the plasma ions do, so aligning to help route the ions in the gauge to the collection grid gives better readings. Even radiation instruments such as photomultiplier tubes can report falsely low readings in the presence of $\mathbf{2 0 0}$ gauss and higher magnetic fields. $4-23$

\subsection{Pump Fire and Explosion Hazards}

In the early days of fusion research, hot oil diffusion pumps were used for generating and maintaining vacuum conditions. The pump oils could volatilize and explode, and have been blamed for backstreaming into the vacuum systems and causing virtual leaks, general uncleanliness, etc. Fortunately, technology has improved, and more reliable (less dirty) pumping methods are now used. Still, there are safety concerns with the cleaner methods of cryogenic and turbomolecular pumping. In cryogenic helium pumps, there is a thermal shield of liquid nitrogen, and in the presence of neutrons, the impure nitrogen can create ozone. $4-24$ The ozone could explosively decompose into oxygen if impacted or if exposed to a static electricity charge. The cryogenic pumps also need to be regenerated periodically, and these pumps devolve hydrogen, deuterium, tritium, water vapor, and oxygen. If safety practices are not followed closely, explosions in pump effluent lines could occur. Hot cathode ion gauges should never be located near cryopump effluent piping, to preclude a chance of igniting a gas explosion. $4-25,4-26$

Turbomolecular pumps have the advantage of not storing up tritium or other gases because they exhaust to a backing pump. The roughing pump effluent gas must be processed carefully, or perhaps diluted with another gas such as helium, to avoid the chance of explosion. Also, leaving 
turbopumps under vacuum while not running can allow backing pump oil to migrate into the pump chamber, then into the vacuum vessel. $4-11$ The only fire concerns are electrical fires from the pump motors.

Oil migration can be arrested by using traps, such as cold traps. These traps provide cryogenically cooled surfaces for gas and oil particles to adhere to, like a cryopump. The same concerns of cryopumps apply to the traps, and they add complexity - welds, coolant piping, etc. to the vacuum system. Proper cleaners for vacuum components are also important to assuring that no fumes linger from virtual leaks in the vacuum systen..4-27

\subsection{Personnel Safety Concerns}

There are several personnel safety concems with vacuum systems. First, workers can get radiation doses near fusion vessels, as they have near accelerator vessels.4-28 Another concern is the release of cryogenic gases from cold traps or cryopumps, which could lead to asphyxiation. Another concern is a worker being pulled into a vacuum chamber by inrushing air. Normal industrial safety concerns (working with welding equipment, using cranes, hoists, or forklift trucks to move heavy vacuum components, using ladders around vacuum systems, etc.) are also present in virtually all fusion experiment facilities.

In the United States, there has been one known fatality involvng a vacuum system. The facility where this event occurred was testing missile nose cones; it is a space simulation chamber. The failed component, an optical vacuum window, was old, perhaps 25 years old. The window failure was attributed mainly to age, although the technician may have inadvertently struck it with a very light blow. The news account is repeated here in its entirety because of the severity of the event:

Lab Technician in Southwest Philadelphia is Killed During Experiment

Robert L. Bendorovich, 63, an equipment technician at a General Electric Co. research laboratory in Southwest Philadelphia, was killed Thursday when an observation window shattered during an experiment at the lab, causing him to be partially drawn into a vacuum chamber, investigators with the Delaware County coroner's office said yesterday.

Investigators said Bendorovich, of Tinsel Road in Levittown, suffered the fatal injuries about 11:30 am at the Skeats High Power Lab. 7500 Lindbergh Blvd. in the Eastwick section, when a round window of the S-foot-long chamber he was standing next to shattered for an undetermined reason. Investigators said suction caused by the vacuum drew him partially into the chamber before his chest became wedged in the 12-inch-wide window.

About two hours later, investigators said, Bendorovich was pronounced dead of asphyxia and chest injuries at Mercy Catholic Medical Center, Fitzgerald Division. The accident was being investigated by the federal Occupational Safety and Health Administration, authorities said.

taken from the Philodelphia lnquirer newspaper

Saturday, September 13, 1986, page B-2 
There are means to preclude such events for large vacuum reservoir fusion experiments. While workers would not be near most future fusion machines because of the superconducting magnet cryostat around the vacuum vessel, the diagnostic penetrations lead to other rooms and must be treated with caution. The first means to preclude injuries due to vacuum system faults is for designers and operations personnel to be aware of the potential dangers. Other precautions for inhabited areas are: multiple vacuum windows, plexiglas or other covers mounted over the windows and other vacuum line penetrations, and barriers to preclude personnel from closely approaching the vacuum system while it is under vacuum.

There is another personnel safety concern, one of electrocution. At high pressures of about 0.1 $\mathrm{Pa}$ and greater, a Bayard-Alpert Gauge creates enough plasma that it can couple to the vacuum chamber. Anyone touching the chamber can become a part of this 'sneak circuit'. Human contact at these $100 \mathrm{~V}$ and modest amperage levels can cause cardiac fibrillation or cardiac arrest. 4-29 Other concerns could be using an incorrect fill gas (the gas used to initially fill the vacuum system on pressurization for maintenance) and having the system pressure increase much higher than gauges calibrated for other gases read out to the operators. $4-30$ This concern is similar to the one given in Chapter 2 regarding using the correct gas for leak detection.

\section{Chapter 4 References}

4-1. M. T. Thomas, "Abstract: The Many Facets of Vacuum Safety," JoumaL of Vacuum Science and Technology, 10, 1973, page 279.

4-2. L. C. Beavis et al., Vacuum Hazards Manual, second edition, American Vacuum Society, 1979, ISBN 0-88318-261-0.

4-3. U.S. Department of Energy, Order 6430.1A, "General Design Criteria," April 6, 1989, section 1328, fusion facilities.

4-4. T. A. Kletz, Leaming from Accidents in Industry, Butterworth Publishers, London, 1988, chapter 4.

4-5. G. Sannazzaro et al., "Low Cycle Fatigue Testing of Inconel 600 and Life Assessment of JET Vacuum Vessel," Proceedings of the 14th Symposium on Fusion Engineering, San Diego, California, September 30-October 3, 1991, pages 385-387.

4-6. G. H. Miley et al., "Influence of High-intensity Radiation on the Properties of Optics for Fusion Diagnostics," Eusion Engineering and Design. 18, 1991, pages 341-348.

4-7. T. Fett and D. Munz, "Lifetime Predictions for Ceramic Windows in Fusion Reactors," Eusion Technology 1988. Proceedings of the 15th Symposium on Fusion Technology, Utrecht, The Netherlands, 19-23 September 1988, pages 899-904. 
4-8. A. Taylor, "On the Survivability of Diagnostic Windows in the CIT Reactor," Eusion Technology, 15, 1989, pages 321-326.

4-9. T. Momose and H. Ishimaru, "Radiation Damages in TRISTAN Vacuum Systems," Joumal of Vacuum Science and Technology, A9, 1991, pages 2149-2157.

4-10. J. P. Bacher and N. Hilleret, "Corrosion of Accelerator Vacuum Systems: Risks and Prevention," Yacuum, 41, 1990, pages 1914-1916.

4-11. M. H. Hablanian, High-Vacuum Technology A Practical Guide, Marcel Dekker, Inc., New York, 1990, pages 242, 252.

4-12. B. J. Merrill and S. C. Jardin, "Consequences of Resistive Disruptions on Vacuum Vessel Components," Ioumal of Nuclear Materials, 145-147, 1987, pages 881-885.

4-13. D. L. Conner et al., "Stress Analysis of a Double-Wall Vacuum Vessel for ITER," Broceedings of the 14th IEEE Symposium on Fusion Engineering, San Diego, California, September 30-October 3, 1991, pages 988-991.

4-14. G. Maddaluno and A. Vannucci, "Activation and Damage by Runaway Electrons on FT Limiter," Journal of Nuclear Materials, 145-147, 1987, pages 697-699.

4-15. H. Hoven et al., "Material Damage in Graphite by Run-Away Electrons," Joumal of Nuclear Materials, 162-164, 1989, pages 970-975.

4-16. K. A. Niemer et al., "Magnetic Field Effects on Runaway Electron Deposition in Plasma Facing Materials and Components," Proceedings of the 14th IEEE Symposium on Fusion Engineering, San Diego, California, September 30-October 3, 1991, pages 372-376.

4-17. H.-W. Bartels, "Runaway Electrons on Plasma Facing Materials," Eusion Technology 1922. Proceedings of the 17th Symposium on Fusion Technology, Rome, Italy, September 14-18, 1992, pages 181-185.

4-18. H. Attaya et al., "Analysis of Forces on Ferromagnetic Components Used in Fusion Reactors," Joumal of Nuclear Materials, 122-123, 1984, pages 96-100.

4-19. L. R. Turner et al., "Measurements of Reactor-Relevant Electromagnetic Effects with the FELIX Facility," Eusion Technology, 10, 1986, pages 1053-1058.

4-20. A. Nishide et al., "Influence of Magnetic Fields on a Large-sized Turbomolecular Pump," Journal of Vacuum Science and Technology, 20, 1982, pages 1105-1108. 
4-21. T. Abe and Y. Murakami, "Development of Ceramic Turbomolecular Pumps for Fusion Devices," Yacuum, 41, 1990, pages 1992-1994.

4-22. H. C. Hseuh, "The Effect of Magnetic Field on the Performance of Bayard-Alpert Gauges," Ioumal of Vacuum Science and Technology, 20, 1982, 237-240.

4-23. J. C. Liu et al., "The Effect of the Static Magnetic Field on the Response of Radiation Survey Instruments," Health Physics, 64, 1993, pages 59-63.

4-24. S. J. Brereton, "Explosion Hazard in Liquid Nitrogen Cooled Fusion Systems," Eusion Technology, 15, 1989, pages 833-838.

4-25. B. A. Hands, "Cryopumping," Yacuum, 37 1987, pages 621-627.

4-26. W. Williams and R. Walker, "Ignition Characteristics of Vacuum System Components," Vacuum, 21, 1971, pages 473-477.

4-27. B. S. Halliday, "Cleaning Materials and Components for Vacuum Use," Yacuum, 37 , 1987, pages 587-591.

4-28. Operational Accidents and Radiation Exposure Experience Within the United States Atomic Energy Commission. 1943-1975, WASH-1192, US Atomic Energy Commission, Fall 1975, Appendix C.

4-29. C. F. Morrison, "Safety Hazard from Gas Discharge Interactions with the Bayard-Alpert Ionization Gauge," Joumal of Vacuum Science and Technology, A3, 1985, pages 2032 2034.

4-30. R. N. Peacock, "Safety and Health Considerations Related to Vacuum Gauging," Journal of Vacuum Science and Technology, A11, 1993, pages 1627-1630. 


\section{VACUUM SYSTEM COMPONENT FAILURE RATES}

\subsection{Introduction}

This chapter contains estimates of failure rates for fusion vacuum components. Fusion and accelerator components function in rather clean environments (cleaner than vacuum manufacturing processes), are baked between 150 and $350^{\circ} \mathrm{C}$, and have little internal contamination. The components discussed here function in the high to ultra-high vacuum range. Most of these failure rates pertain to vacuum leakage, while some refer to loss of component function, such as loss of pumping ability. The components are discussed in order of pumps, flanges, electrical feedthroughs, bellows feedthroughs, vacuum gauges, and windows. Vacuum ducts and vessels are briefly mentioned. The failure rates given here are steady-state values, that is, the rate at which random failures occur during the component's useful life, not early failures (uncovering latent defects, manufacturing faults, installation errors, etc.) or end-of-life failures (wearout). For early failures, the failure rate can be much higher than the steady state value. Electronic components might nave decreases of factors of 3 to over 100 from early life to the steady state value, 5-1 and mechanical components such as remotely operated valves and compressors have been seen to decrease by factors of 3 up to 20 between early and useful life. 5-2 For electronic components, 10,000 hours is the typical crossover time between early and useful life. 5-1 For mechanical components, that time could be shorter. Error factors are either calculated from the data, or they are assigned based on known information. When assigned, they are chosen conservatively, to reflect the uncertainty in the estimated failure rate value. A table at the end of this chapter summarizes the results.

\subsection{Pumps}

There are many kinds of vacuum pumps. There are pumps for different pressures and a variety of pump types for a given pressure range. For example, there are mechanical pumps for high pressures ( $1 \mathrm{E}+05 \mathrm{~Pa}$ to $1 \mathrm{~Pa}$ ) that range from carbon vane pumps, scroll pumps, roots blowers, to reciprocating piston pumps. Cryosorption pumps can operate in the same range, and are regarded as cleaner operating units. Some turbopumps can also operate at atmospheric pressure as roughing units. For high vacuum, in the $1 \mathrm{E}-01 \mathrm{~Pa}$ to 1E-04 $\mathrm{Pa}$ range, there are ion pumps, turbopumps, getter pumps, and sublimation pumps. The main pumps for future fusion experiments will be mechanical roughing pumps (for evacuation to the 1 to $0.1 \mathrm{~Pa}$ range), turbopumps, cryopumps/cryopanels, and secondary (mechanical) pumps on the turbopump exhaust. These pumps will receive the most treatment here, but the other types will be briefly addressed. Also, reference 5-3 contains some helpful design ideas for safety in various vacuum pumping systems.

Turbopumps. For fusion, these pumps have speeds (capacities) of perhaps 5,000 to $7,000 \mathrm{l} / \mathrm{s}$, and the rotors turn at high speed, perhaps up to $40,000 \mathrm{rpm}$. Such high rotor speeds require good lubrication for the bearings, or perhaps the relatively recent approach 
of a magnetically levitated rotor. ${ }^{5-4}$ The magnetic bearing pumps are still small (560 V/s) and cost twice as much as the more conventional pumps, so it is likely that ITER or other near term machines would use the larger mechanical bearing units. Bearing life has been viewed as the limiting feature to turbopump reliability, although ceramic bearings seem to provide longer life than metal bearings. $5-5,5-6$ The bearings should be overhauled every $10,000$ hours (just over one year). For a small turbopump ( $260 \mathrm{l} / \mathrm{s})$, the drive belt and oil change take 2 or 3 hours, outside of radiation areas (the pump is located outside the radiation shielding).5-7 With the bearing life limitation on the turbopump, other reliability characteristics are not as significant, unless there are rotor eddy current effects that load the bearing with unnecessary forces, $5-8$ heat causes rotor warping, or perhaps air inleakage through the casing. There were no cases of air inleakage through the casing in any of turbopump reliability literature reviewed for this report, so that failure mode is apparently rare. The turbopump can experience backstreaming through the secondary pump (or forepump) aligned to the turbopump exhaust when there is an interruption in service. When the power is lost, for example, then the vacuum in the chamber overwhelms the pumping ability of the secondary pump, creating a reverse flow path. In these cases secondary pump oil could flow into the chamber. $5-3$ Turbopumps are used because they are very clean, they have good pumping speed, fast on-line capability (a few minutes compared to other pumps that can take closer to an hour), good recoverability in brief (minutes) power interruptions, and no tritium buildup or potential explosion concerns. These pumps do, however, communicate their effluent outside the vacuum chamber, so there must be fast closing valves to isolate the pump lines in case of an unusual event (power loss, improper command signal to shut down, etc.), a means to vent the pump backpressure to mitigate any oil migration, and a continuous means to clean up the effluent (as opposed to batch cleanup when regenerating cryopumps). ${ }^{5-3}$

Given that the bearings are the life limiting component of these high speed pumps, then information from Table 1 of reference 5-5 for $\mathrm{N}$ large turbopumps gives an average failure rate of $(0.1 \mathrm{~N}) /(11,000 \mathrm{~N})=9 \mathrm{E}-06 /$ hour for the turbopump itself failing to operate because of greased ceramic bearing failure. For a large turbopump with greased metal bearings, the failure rate would be $1.3 \mathrm{E}-05 / \mathrm{hour}$. Other possible operation limiting failures (drive motor, etc.) should be smaller contributors than the bearing failures. A small error factor of 3 is assumed for these data because they have a wide operating basis. Leakage of air from the pump to the system should be a combination (addition) of flange leakage and casing leakage. Flange leakage is treated later in this chapter, and casing leakage is a low failure rate event, about 5E-03/year (based on thin wall storage tank breach failure rates in reference 5-9; an error factor of 10 is assigned to the leakage failure rate since this is a wide extrapolation to the pump casing). A notable item here is that magnetic bearing turbopump experience thus far has been found to be excellent. ${ }^{5-10}$ The mechanical pump that draws the turbopump exhaust is discussed next.

Mechanical roughing pumps. These pumps typically move air by positive displacement, and can only operate to certain inlet pressures (perhaps down to 10 to $1 \mathrm{~Pa}$ ) 
because they would overheat when drawing out more air. Piston pumps, vane pumps, and others are considered here. Mechanical pumps for either turbopump backing or rough pumping a chamber are generally regarded as reliable devices, only requiring an oil change each year. Belt driven pumps that operate at low speeds may last for 10 to 20 years of continuous operation. Modern high speed pumps, such as vane pumps, may last 5 to 10 years of continuous operation.5-11 For the modern pumps, an average failure to operate failure rate is $1 / 7.5$ years, or $1.5 \mathrm{E}-05 /$ hour. The upper bound for this failure rate would be $1 / 5$ years or $2.3 E-05 /$ hour. For air leaks through the casing of a mechanical pump, the flange leakage failure rate and a casing leak failure rate must be added. The casing leak failure rate should be similar to the turbopump casing value of 5E-03/year, unless there are flanged halves of a pump body.

Oil migration into the vacuum system is often not the fault of the pump unit, but a matter of improper operational practices. $5-3$ Since power failures could justifiably lead to oil migration, the site power loss frequency should be used as a first approximation to quantify the frequency of oil backstreaming into the vacuum system. If there is an isolation valve, then it must be considered as a mitigator to system contamination.

Roots blowers have a large leakage failure rate estimated by Sarto et al. $5-12$ for the NET device as 5E-06/hour. This failure rate is considered to be an upper bound. The modern mechanical pump failure rate of $1.5 \mathrm{E}-05 /$ hour is a reasonable estimate for this type of pump.

Cryosorption pumps. These pumps are usually roughing pumps and are very clean because no pump mineral oils or other contaminants are used. These pumps adsorb gases (air, water vapor, etc.) onto zeolite molecular sieve pellets that are cooled to liquid nitrogen (LN2) temperatures. These units are simple - a chamber housing the zeolite pellets, an isolation valve, a vent line, a bakeout heater, and an outer jacket for the LN2 bath. From vendor catalogs, typical cryosorption pumps could be $120 \mathrm{~mm}$ in diameter and $320 \mathrm{~mm}$ tall, with a $38 \mathrm{~mm}$ diameter line connection to the vacuum system, and a $1.4 \mathrm{~kg}$ charge of zeolite. Possible failure modes could be zeolite breakout with subsequent migration into the vacuum system, and pump loss of integrity (breach to the atmosphere). Zeolite breakout would be a low frequency event, since pump construction specifically holds the pellets with screens, plates, and other retention methods. The failure rate for the breakout failure mode is considered to be much less than rates for other failure modes, so it is not quantified here.

The cryosorption pump can be baked at up to $300^{\circ} \mathrm{C}$ to regenerate the zeolite by driving out the air, water vapor and other entrapped vapors. Zeolite can last long periods of time, perhaps 15 to 20 years, with low use (roughing systems are typically used infrequently, perhaps every 6 months or so), proper storage, and infrequent bakeout at $300^{\circ} \mathrm{C}$ or lower (higher temperature bakeout at perhaps $600^{\circ} \mathrm{C}$ will damage the zeolite [noted in a vendor catalog]). With proper care and no contamination, the zeolite is very 
resilient and could last perhaps up to $\mathbf{5 0}$ years. If the system has significant oil or other hydrocarbon contamination to clog the zeolite pellets, then the zeolite may only continue to pump for 1 or 2 years. Or, if irradiated or highly vibrated, the zeolite could break down and lose its adsorption properties. Also, if an appreciable amount of tritium got onto the zeolite, say $1,000 \mathrm{Ci}$, then it might be easier to dispose of the pump's $1.4 \mathrm{~kg}$ zeolite load than to verify that all of the tritium had been removed by baking. With a lifetime of between 15 and 50 years, the failure rate for the failure to operate mode will be dominated by the availability of liquid nitrogen. The LN2 availability is not a fault of the cryosorption pump, but can be treated with data from another report. 5-13 The pump casing should be as sturdy as the others cited here, even though the sorption pump stainless steel casing undergoes extreme thermal cycling ( $77 \mathrm{~K}$ to room temperature to $573 \mathrm{~K}$ for bakeout). Welds in the pump casing are kept to a minimum or are eliminated entirely, so the leakage failure rate of 5E-03/year should be a reasonable estimate for pump casing air inleakage. The flange leakage failure rate should be used for the pump connection to the system. The vent line has only a rubber or polymer sleeve to cover the vent hole, but this is a basically reliable system. The only troublesome issue would be if ice built up in the vent line during outgassing, causing a casing rupture on overpressure. With good pump design and orientation, such ice buildup should be a rare occurrence, in the 1E-02 to 1E-04/year frequency range. The average failure rate for that event should be 1E-03/year. The upper bound would be 1E-02/year, given that the cryosorption pump is used infrequently (a few times a year).

Cryopumps. These pumps use liquid helium (LHe) or very cold gaseous helium for coolant, and LN2 for their thermal shields. The pumps are a complicated set of piping, with the thermal shield and cooling panels in the central portion of the pump. Pumping speeds could be 9,000 1/s or higher, which is an advantage over turbopumps. $5-14$ These pumps have flowing coolant, so their reliability is more complex than that of 'bath-cooled' sorption pumps. Failure modes would be loss of cryogen into the vacuum system, air inleakage through the pump, and failure to operate. The JET experiment analyzed the failure rate of their neutral beam cryopumps (large units) to leak cryogen into the vacuum chamber. They found a tentative value of $2 \mathrm{E}-05 /$ hour.5-15 Using a $95 \%$ chi-square distribution $5-16$ on no failures over the pump's operating time period ( $5 E+04$ hours) gives an upper bound failure rate of $5.99 / 2 * 5 \mathrm{E}+04 \mathrm{~h}=6 \mathrm{E}-05 / \mathrm{hour}$. The failure rates from the JET experience are reasonable, but it should be noted that continued operation could lead to even smaller failure rates. The leak size is assumed to be small, since in this application, even small leaks exhausting to vacuum will probably pressurize from wall heat, thus leading to overpressurization of the vacuum vessel. For cryopump air inleakage, the reader must remember that these pumps must have provisions for protection against heat leakage, and this includes air inleakage. For the Next European Torus (NET) fusion design, Sarto et al.5-12 used 7E-06/year for cryopump large air inleakage. An error factor of 10 should be used with this value, since it was assumed based on performance of thick, single-walled vessels. That value should include the rupture disk or other pressure relief device on the cryopump casing. 
The cryopump failing to operate can only happen if the cryogen supply is lost, the thermal shield fails, the thermal shield is thermally short circuited, or if the system becomes plugged (loss of flow accident). Loss of cryogen can be addressed by using information in another report. $5-13$ The only failure mode attributable to the cryopump itself is plugging its piping. Plugging should be of the same frequency as small pipe ruptures, $5-17$ so the JET cryopump value of $2 \mathrm{E}-05 /$ hour for leakage into the vacuum system should be reduced by a factor of 10 to arrive at a cryopump pipe rupture frequency, $5-17$ which is roughly the same as a pump failure by plugging failure mode. Therefore, $2 \mathrm{E}-06 / \mathrm{hour}$ with an error factor of $\mathbf{1 0}$ describes the failure rate for cryopump plugging.

Sublimation pumps. This type of pump, mainly the titanium sublimation pump, removes gases by chemical combination. For example, the titanium forms TiN with nitrogen to remove the nitrogen from the vacuum chamber. Titanium filaments that weigh a few grams are heated, evaporating titanium from the filament so that it can combine with gases and later the compounds (TiN, etc.) will adhere to the chamber walls. The titanium on the walls also forms a nascent surface that reacts with more gas molecules, thus reducing gas pressure in the chamber. $5-11$ The emitted titanium must be physically separated from other components, such as ion pumps, ionization gauges, and cryopumps so that the compounds do not damage these other components. An individual titanium filament might last 8 hours under continuous pumping before breaking. $5-18$ Multiple filaments are built in to the pump, so there is a casing-to-chamber flange, the casing itself, and the filament electrical feedthrough that might leak. In Chapter 2, Table 2, the LEP accelerator showed its leakage experience with getter pump feedthroughs. Over a 24 hour bake of 3,942 getter pump feedthroughs, 7 had small leaks. This gives a feedthrough leakage failure rate of $7 / 3942 * 24 \mathrm{~h}=7.4 \mathrm{E}-05 / \mathrm{hour}$. A $95 \%$ upper bound would be the Chi-squared distribution on 7 failures (that is, 16 degrees of freedom, 2(7)+2), or $26.3 /(2 * 3942 * 24)=1.4 \mathrm{E}-04 / \mathrm{hour}$. The casing leak rate of $5 \mathrm{E}-03 /$ year as discussed earlier is also applied to the titanium sublimation pump casing, if it has a separate casing. Flanges are discussed later in this chapter. For the pump failing to operate, there could be a loss of power (attributed to a power supply), wire overheat due to foreign material plateout or wire short circuit due to foreign material (both assumed to be in the 1E-02 to 1E-04/year event category), or premature wire open circuit. A premature open circuit for the titanium wire is taken to be $2.3 \mathrm{E}-07 / \mathrm{hour}$ per filament, based on $3 \mathrm{~m}$ lengths of copper wiring in power plants $5-19$ and filaments of $0.3 \mathrm{~m}$ length. A typical pump might have four filaments (vendor advertisements promise pump lifetimes of more than 30 hours), so the sublimation pump failure rate for the fail to operate mode is $9 \mathrm{E}-07 / \mathrm{hour}$. The upper bound failure rate is $3 \mathrm{E}-06 /$ hour for an error factor of 1.7 . Larger pumps with many long filaments would have to be calculated accordingly.

Non-evaporable getter (NEG) pumps would likely have lower failure rates than sublimation pumps, since the getter (such as $\mathrm{Zr}$ - $\mathrm{Al}$ ) remains basically intact. The high temperatures (hundreds of degrees $\mathrm{C}$ ) do not seem to deteriorate these pumps. Many accelerators use NEG pumps built in at the periphery of the beam tube giving up to $500 \mathrm{~V} / \mathrm{s}$ 
pumping per meter of beam tube length, and these pumps give reasonable to good service in the large quantities that accelerators employ them.5-20 Unfortunately for this report, no good data on these pumps have been obtained from the literature. Therefore, using the average titanium sublimation pump failure rate for the upper bound failure rate of NEG units is assumed until more data can be obtained.

Ion pumps. There are diode and triode ion pumps. O'Hanlon ${ }^{5-20}$ gives lifetimes for these pumps on a basis of pressure in the system. For diode pumps, an average life of about 5,000 hours at $1 \mathrm{E}-03 \mathrm{~Pa}$, and 50,000 hours at $1 \mathrm{E}-04 \mathrm{~Pa}$. The triode pump has half the life of the diode unit. The diode pump lifetime is verified by field experience $5-21$ of 500 Watt diode units that achieve 1E-06 Pa; these units reached 6 years of operation before becoming very difficult to start - the sign of pump aging. Ion pump problems could be internal short circuits that cause failure to operate, and casing leakage. Assuming proper system cleanliness and rough pumping, then the lifetime of $1 / 50,000$ hours gives a failure rate of $2 \mathrm{E}-05 /$ hour for the failure to operate failure mode. A small error factor of 3 is assigned to this failure rate for diode ion pumps because field experience supports the average lifetime estimates. Triode pump failure rates are double those of diode pumps. The pump casing leakage failure rate involves a flange, the casing (at 5E-03/year, as with other casings), and ion pump feedthroughs. From Table 2 in Chapter 2, the ion pump feedthroughs are 1,908 in number. With 7 leakage failures, this gives $7 / 1908 * 24 \mathrm{~h}=$ $1.5 \mathrm{E}-04 / \mathrm{hour}$. A $95 \%$ chi-squared distribution upper bound would be $26.3 / 2 * 1908 * 24=$ $2.9 \mathrm{E}-04$ /hour.

Ejector pumps. Another type of pump to consider is the ejector pump, where high speed fluid flow from a nozzle near the main chamber entrains gas molecules, then the flow with entrained gases enters a funnel region, creating a vacuum in the main chamber. Steam ejectors are often used on power plant condensers to keep the pressures down in the 6,000 to 7,000 $\mathrm{Pa}$ range, and large, multi-stage ejectors can develop even lower pressures of 1 to $20 \mathrm{~Pa}$. $5-22$ Steam jet ejectors used on condensers at fossil fueled power plants have failure rates (air leakage and loss of function modes combined) on the order of 7E-06/hour. $5-23$ An error factor of 10 is assigned to this value, since these source data are speculative. The possibility of using cryogenic fluid ejector pumps has been suggested for ITER, and this failure rate would have to suffice for such a pump until it could undergo life tests and more detailed examination.

\subsection{Flanges}

The vacuum flanges considered here are all metal sealed, because of radiation concems with fusion systems as mentioned in Chapters 2 and 4. Elastomer seals do not have good irradiation life, and even particle accelerators with less irradiation than fusion experiments use metal gaskets in their flanges. In some interesting work on CERN stainless steel flanges, 6,000 units were examined over a 14 year period. These flanges typically contained 1E-06 Pa pressure, were under mild irradiation ( $x$-rays and gamma 
rays), and had infrequent $300^{\circ} \mathrm{C}$ bakeouts. The $160-$ to $215-\mathrm{mm}$ diameter flanges had a small leakage failure rate of 5.7E-04/flange-year, and the larger flanges of 295- to 325-mm diameter had leakage failure rates of 3E-03/flange-year. $5-24$ These results are much better than those reported in Table 2-2, which would indicate about $0.2 /$ year for $225 \mathrm{~mm}$ diameter flange leakage after installation bakeout. The 14 year period does lend confidence that the flanges are properly tightened over time. Still, the fusion results from JET show higher leak incidence by about a factor of 20 , so the CERN values will be increased by that factor to account for the more harsh fusion conditions. Therefore, for the smaller diameter, the flange leakage failure rate is about $1 \mathrm{E}-03 /$ year, and the larger failure rate is $6 \mathrm{E}-02 /$ year. The leakage value is assumed to be on the order of $1 \mathrm{E}-07$ to $1 \mathrm{E}-08 \mathrm{~Pa}-\mathrm{m}^{3} / \mathrm{s}, 5-22$ since accelerators with their configuration of a small beam tube diameter (less than $1 \mathrm{~m}$ ) and large circumference (several $\mathrm{km}$ ) cannot handle very large localized air leaks without loss of the beam. The error factor for these failure rates is assigned to be 3 , since this is a wide data set of many components over a long time period.

Larger flanges are expected to have larger leak rates, since there is more sealing area to develop a leak. Extrapolating to larger size flanges, such as $1 \mathrm{~m}$ diameter, gives a failure rate of $2.5 \mathrm{E}-02 /$ year. Increasing this failure rate by the factor of 20 gives $5 \mathrm{E}-01 /$ year. Until more work can be done to define large flange reliability, this value will have to suffice. An error factor of 10 is used on this extrapolated value. Another feature of flanges is their bolts. A typical bolt failure rate for loss of tension (by metal fatigue, thermal fatigue, or shear, etc.) is $2 \mathrm{E}-08$ /hour, $5-25$ with an error factor of 10 .

\subsection{Electrical Feodthroughs}

Electrical feedthrough air inleakage for sublimation and ion pumps have already been discussed in this chapter. Beam position ceramic feedthroughs for the LEP accelerator in Table 2-2 are very similar to the feedthroughs fusion experiments would use for their own diagnostics. With 5 leakage failures out of 2,168 ceramic units over a 24 hour period, the leakage failure rate is $5 /(2168 * 24 \mathrm{~h})=9.6 \mathrm{E}-05 / \mathrm{hour}$, or with round-up, about 1E-04/hour. The 95\% chi-squared distribution upper bound would be $21.0 / 2(2168 * 24 \mathrm{~h})=2 \mathrm{E}-04 / \mathrm{hour}$. This leakage failure rate for the feedthroughs is reasonable to use for fusion devices, but since the JET experience shows about a factor of 5 increase in the feedthrough leakage, this failure rate and its upper bound will be increased by that amount. The air inleakage failure rate for ceramic feedthroughs is $5 \mathrm{E}-04 / \mathrm{hour}$, and the $95 \%$ upper bound is $1 \mathrm{E}-03 /$ hour.

JET also noted problems with electrical feedthrough arcing, but the problem was corrected with a change in the method of operation, as discussed in Chapter 2. No failure rate for arcing will be given here, but for safety reasons, future designs must be investigated to verify that gas pressures (Paschen curves for voltage breakdown of gas at various pressures) will not be conducive to arc events at or near the feedthroughs. 


\subsection{Bellows Feedthroughs}

Bellows were the leading cause of vacuum outages at JET. The tokamak environment is harsh for metallic bellows, with vibration, some irradiation, and thermal cycling. The vacuum vessel stainless steel and other metallic bellows have given rise to leakage problems on the large machines, but only smaller bellows units will be discussed here, since future fusion designs call for vacuum vessels with solid wall construction.

The LEP accelerator used 3,122 bellows units, and had 3 leaks over the 24 hour bakeout. That gives a leakage failure rate of $3 /(3122 * 24 \mathrm{~h})=4 \mathrm{E}-05 / \mathrm{hour}$. The $95 \%$ chisquare distribution upper bound failure rate for 8 degrees of freedom would be $15.5 / 2 * 3122 * 24 \mathrm{~h}=1 \mathrm{E}-04 / \mathrm{hour}$. For comparison, water system bellows units have leakage failure rate averages in the range of $2 \mathrm{E}-06$ to $5 \mathrm{E}-06 /$ hour, $^{5-26}$ thus demonstrating that analogies between water coolant and other systems are not always reasonable. The JET experience was less reliable than the LEP, with 20 times the number of bellows leaks, so the LEP failure rates will be adjusted to better align with existing tokamak environmental stresses. This is done since future experiments will still be subject to the same stresses: thermal cycles for bakeout; high vibration from the plasma, the magnet forces, and the pumps; and perhaps high irradiation. If each of these concerns received a factor of 3 increase to the basic failure rate, $5-27$ the combined effect would be 27 rather than just 20 , thus providing an example of the slight conservatism of reliability prediction using multiplicative factors. For fusion metallic bellows leakage, the average failure rate should be $8 \mathrm{E}-04$ /hour and the $95 \%$ upper bound should be $2 \mathrm{E}-03$ /hour. While there could be several bellows failure modes (tearing, fatigue, squirm, etc.), only the resultant leakage is of our concern here. The LEP leak rate value for bellows leaks was estimated to be about $3 \mathrm{E}-12 \mathrm{~Pa}-\mathrm{m}^{3} / \mathrm{s}$, but for fusion, the leakage value is probably much higher, on the order of 1E-06 Pa-m $3 / s$.

\subsection{Vacuum Gauges}

There are several kinds of vacuum gauges. Hot cathode ionization gauges, such as the industry workhorse - the Bayard Alpert Gauge (BAG), and cold cathode gauges, such as the Penning gauge. Pirani gauges are also used in fusion experiments. BAGs are used for lowest pressures (in the $1 \mathrm{E}-05 \mathrm{~Pa}$ range), Penning gauges for the 1 to $1 \mathrm{E}-04 \mathrm{~Pa}$ range, and Pirani gauges in the 1 to $1 \mathrm{E}-03 \mathrm{~Pa}$ region.

Experience with BAGs from the SRS synchrotron shows that 16 tubular units have performed reliably (neither leaking or failing to function) over 7 years. ${ }^{5-28}$ For zero failures, reference 5-16 gives the Chi-squared distribution as the formula for the leakage and failure to operate failure rates, therefore $1.39 / 2 * 16 * 7$ yrs $=6 \mathrm{E}-03 /$ year for either failure mode. The 95\% upper bound would be 5.99/2*16*7 =3E-02/year. There could be arguments that this failure rate and upper bound are much too conservative; in fact, in reference 2-19 gives information that BAGs have been used on sequential facilities, so 
these units could last for tens of years. The estimate here is reasonable until vendor information or a wider set of BAG data becomes available for reliability analysis. Since the BAGs did not fail to operate or leak air into the vacuum system (including their flange connection to the vacuum chamber), this failure rate is the same value for both failure modes. As discussed in Chapter 2, however, the BAG inaccuracy could vary by as much as $\pm 30 \%$. The BAG also usually requires an amplifier to boost the signal out, which is another component to include when figuring instrumentation and control system reliability.

Cold cathode gauges, such as the Penning gauge, are thought to be more reliable longer lived and more rugged - than hot filament gauges.5-29 The Penning gauge requires a small permanent magnet; as discussed in Chapter 2. These Penning magnets have moved in the JET magnetic field, causing the gauges to breach vacuum or at least to send incorrect pressure readings. If the Penning gauges are set up correctly, then their failure rates should be lower than those of the BAGs. Therefore, the Penning gauge upper bound is set equal to the BAG average value.

Pirani gauges are wheatstone bridges, where one segment is in a vacuum tube. Since the wheatstone bridge is similar to a strain gauge, then for a first approximation to the failure to operate failure mode, a value of $2.5 \mathrm{E}-07 /$ hour $^{5-25}$ is used. An error factor of 10 is used because of this extrapolation of components. For the air inleakage failure mode, the same value for tubular BAGs is used. If a semiconductor is used as the sensitive element, then the Pirani gauge is technically a thermistor gauge, but since thermistors have failure rates of $1 E-07 /$ hour, $5-26$ there is only a $40 \%$ difference to the given failure rate. This difference can be accounted for if the reliability analyst is analyzing a thermistor gauge.

Rough vacuum gauges, such as Bourdon gauges, are generally simpler than high vacuum gauges. However, they are likely to require periodic calibration. Therefore, an analyst judgment failure rate of 1E-04/hour for the gauge failing to operate properly should be used in the absence of other data. The air inleakage failure rate for these gauges is that for a small flange.

\subsection{Vacuum Windows}

The JET experiment has estimated the failure rate for small optical (quartz) window breach failures of 1.4E-06/window-hour or 1.4E-06/window-discharge. The upper bound for these values would be $5.99 / 2 * 35 * 2 \mathrm{E}+04 \mathrm{~h}=4.3 \mathrm{E}-06 /$ window-hour, or per windowdischarge. Both rates are calculated because JET safety personnel were unsure if hours at vacuum or the stresses associated with plasma discharges were more dominant for window lifetime. Perhaps the discharges create more stresses from vibration, high temperature, and irradiation than stresses from simple hours under vacuum. Windows can also brown out, that is, discolor from irradiation. There are no data on the time duration for typical window browning, although it is an age related phenomena. The JET value is for small optical (quartz) windows, but this operating experience value is suggested for use in future 
experiments. Other windows, such as thin metal or ceramic windows, do not have as much data available. Accelerators have had problems with these windows breaching from heat increases due to foreign material buildup. Until more data can be found, the JET value should be used for any window, unless analyst judgment provides better insights.

\subsection{Vacuum Valves}

There are several kinds of vacuum valves. There are gate valves, poppet valves, and angle valves, both manual and operator driven. Here we concentrate on gate valves, since these are used in fusion devices. There are several failure modes of interest; failing to transfer on command (fail to open or fail to close), spurious transfer, external air inleakage, and leakage past the valve seat. Plugging is only a concern for valves that can develop icing conditions.

Typically, vacuum valves will have bellows on the stem to maintain vacuum if the stem seal leaks. Gate valves would probably be configured to fail closed on a loss of power. Normal gate valve closing times could range from $0.3 \mathrm{~s}$ to $3 \mathrm{~s}$, depending on their size.5-30 A large all metal gate valve was tested for JT-60.5-31 In that test, the valve was exercised 4581 times at room temperature, and 2619 times at $275^{\circ} \mathrm{C}$. The valve did not appreciably leak past the seat in any of those exercises, nor did it fail to operate or spuriously transfer position. For zero failures, a chi-square distribution $5-16$ gives the average failure rate of $1.39 / 2(4581+2619)=9.7 \mathrm{E}-05 /$ demand; this value is rounded up to $1 \mathrm{E}-04 /$ demand. The $95 \%$ upper bound for this valve test would be $5.99 / 2(4581+2619)=$ 4E-04/demand. This 1E-04/demand failure rate is in the same range as the testing rezults of a large bellows valve. 5-32 However, the time of the testing was insufficient for a good failure rate for leakage past the seat.

External leakage for large vacuum valves has been estimated by Sarto et al. $5-12$ as 2E-07/hour, with an assigned error factor of 10 since this value is derived from water system information. If the valve has two bellows (an inner bellows inside the valve casing that connects to the valve disk and the interior of the casing, and an outer bellows that attaches to the stem and the exterior of the casing), then the second bellows leakage failure rate should be on the order of 2E-06/hour (again, an error factor of 10 should be used on these valves). Many valve designs call for only one interior bellows. These bellows should not be gasketed with elastomer seals.

Spurious change of position (opening or closing without request) is more a matter of valve operator than if the valve is a gate or globe valve. Some failure rates for spurious transfer are: motor operated valve, 5E-08/hour, error factor 10, for an air operated valve, 3E-06/hour, error factor of 10, and for a solenoid operated valve, 5E-07/hour, error factor of 10.5-33 These are reasonable values to apply to fusion valves, if there are no outside influences, such as varying magnetic fields causing currents in solenoid operators, air control solenoids, or motor windings. 
Leakage past the valve seat has been discussed in Chapter 2. Dust and other debris can score the seat and allow leak paths. To approximate this effect, a check valve leakage past the seat in a water system is used here. That value would be 3E-06/hour, with an error factor of 10.5-33 For this extrapolation to vacuum valves, we shall use an error factor of 30.

\subsection{Vacuum Ducts and Vessels}

Vacuum piping has been considered similar to water system piping in nuclear fission plants. A typical stainless steel vacuum spool piece wall thickness might be $3 \mathrm{~mm}$, but comparable diameter fission piping might be 2 to 4 times as thick. While fission piping is much heavier walled than vacuum piping/ducting, there is no good data available for vacuum pipe spool pieces or fittings. As a first approximation, use of fission piping data to apply to vacuum pipes/ducts is reasonable. For piping external leakage, 1E-08/hour-m (error factor of 10, but increased here to 30), and tank leakage of 1E-08/hour (error factor of 10, but increased here to 30 ) are reasonable values. $5-34$ Rupture values are a factor of 100 lower for high quality piping.

Fusion vessel breaches, of the vessel walls (not windows, etc.), are an area of great controversy. Several analogies have been drawn; to thin-walled pressure vessels, to thick walled fission reactor pressure vessels, to fossil fuel boilers, etc. Operating experiences have produced estimates between 1E-03 to 1E-05/year. $5-35$ In the next chapter, a value of 5.7E-05/year for a 25\% available fusion experiment is adopted from the NET studies. Weld failure rates should be quantified using work by Buende et al., 5-36 since that data set is the most comprehensive available for fusion systems.

\subsection{Other Components}

Some other components that might be used are filters, either solid filters, such as high efficiency particulate air filters, or electrostatic filters to remove dust or other debris to keep the vacuum system uncontaminated. Leakage failure rates for these components were given by Sarto et al.5-12 as 3E-07/hour. Error factors of 10 are assigned to these component failure rates since the rates are assumed from other experiences. The failure rate for failure to operate for electrostatic filters was 1E-05/hour from Sarto5-12 (note electrostatic precipitators in coal plants have a failure rate of about $5 \mathrm{E}-05 / \mathrm{hour}^{5-23}$ and the differences in operating environments should easily account for the factor of 5 difference). The solid filter failure to operate failure rate from Sarto5-12 was about 7E-06/hour. An error factor of 10 is assigned to this value. Another component is the rupture disk. This component can have three failure modes of interest, early opening at pressure below rated pressure, leakage, and failure to open on demand.

Rupture disks for overpressure protection can also be used on fusion vacuum vessels. Rupture disks for water systems have an 'all failure modes' failure rate value of 
3E-06/hour. 5-37 I assume an error factor of 3 for this failure rate. This failure rate value is a reasonable first approximation for rupture disks to use on gas systems, using the full value for premature opening, leakage, and failure to open at rated pressure.

Table 5-1 contains a list of failure rates estimated in this chapter. These are our best estimates at the present time, until vendor data or more fusion experience data are obtained. These failure rates presented here should reflect fusion conditions without the need of any multiplicative factors to account for harsh conditions (vibration, irradiation, thermal cycling, etc.) since these data have either originated in fusion conditions, are already scaled according to JET results, or are components that do not reside within the area of harsh fusion conditions (such as behind the radiation shields, isolated from vibration; for example, the vacuum pumps). These failure rate data can be used for existing and next generation experiments. 
Table 5-1. Vacuum system component failure rate estimates

\section{Component}

Large turbopump

ceramic bearing fails to operate metal bearing fails to operate casing leakage

Mechanical roughing pump

high speed pump (vane, etc.)

fails to operate

casing leak

roots blower fails to operate

roots blower casing leak

Cryosorption roughing pump

fails to operate

casing leak

Large cryopump

fails to operate (plugged)

leak cryogen into vacuum chamber

casing leak

Small titanium sublimation pump

fails to operate

(premature filament open circuit)

feedthrough leak

casing leak

Non-evaporable getter (Zr-Al) pump

fails to operate

casing leak
Eailure mite

9E-06/hour

1.3E-05/hour

5E-03/year

error factor 3

error factor 3

error factor 10

Associated error

$\begin{array}{ll}1.5 E-05 / \text { hour } & \text { error factor } 1.2 \\ \text { 5E-03/year } & \text { error factor } 10 \\ 1.5 E-05 / \text { hour } & \text { error factor } 1.2 \\ \text { 5E-06/hour (upper bound) }\end{array}$

Low failure rate; use availability of liquid nitrogen supply, since zeolite can continue to function indefinitely under good conditions

5E-03/year

error factor 10

2E-06/hour

error factor 10

2E-05/hour

error factor 1.7

7E-06/year

error factor 10

9E-07/hour

error factor 1.7

7.4E-05/hour

error factor 1.4

3E-05/year

error factor 10

9E-07/hour (upper bound)

3E-05/year

error factor 10 
Small ion pump

diode pump fails to operate

casing leak

feedthrough leak

Large ejector pump

all modes

(air leak, working fluid leak, and fail to operate [plugged])

Metal gasket flanges

160 to $215 \mathrm{~mm}$ diameter leakage

295 to $360 \mathrm{~mm}$ diameter leakage

$1 \mathrm{~m}$ and larger diameter leakage

flange bolt

Electrical feedthrough for diagnostics leakage

5E-04/hour

8E-04/hour

leakage

2E-05/hour

3E-05/year

7E-06/hour

1E-03/year

6E-02/year

5E-01/year

2E-08/hour

Metal bellows
1.5E-04/hour

error factor 3

error factor 3

error factor 10

error factor 10

error factor 1.4

Bayard Alpert hot filament ionization gauge all modes

6E-03/year

(same value for failure to operate and tubular gauge leakage)

Penning cold cathode ionization gauge

all modes

(fail to operate, leakage) error factor 3

error factor 10

error factor 1.4

error factor 10 


\section{Component}

Eailure rate

Associated error

Rough vacuum gauges

fail to operate

1E-04/hour

error factor 10

leakage

1E-03/year

error factor 3

Vacuum windows (quartz optical viewports)

leakage

1.4E-06/discharge or

1.4E-06/hour

error factor of 1.8

this value should be used for other windows (metal or ceramic) until future data on windows becomes available.

Valves

fail to operate on demand

1E-04/demand

error factor 2

(fail to open or fail to close)

spurious open or close

motor operated

air operated

5E-08/hour

error factor 10

solenoid operated

3E-06/hour

error factor 10

5E-07/hour

error factor 10

external air leakage

2E-07/hour

error factor 10

internal leakage across the seat

3E-06/hour

error factor 30

Vacuum piping and ducts

piping leakage

$1 E-08 / h-m$

error factor 30

tank leakage

1E-08/hour

error factor 30

(rupture values are a factor of 100 lower than the leakage estimates)

Vacuum vessel

wall breach

5.7E-05/year (for 25\% availability)

Filters

electrostatic filter leakage

3E-07/hour

error factor 10

electrostatic filter fail to operate

1E-05/hour

error factor 10

solid filter leakage

3E-07/hour

error factor 10

solid filter fail to operate

7 E-06/hour

error factor 10 


\section{Chapter 5 References}

5-1. D. J. Klingler et al., editors, AT\&T Reliability Manual, Van Nostrand Reinhold, New York, 1990, pages 25-36.

5-2. L. C. Cadwallader and G. L. Taylor, Experimental Tritium Cleanup System Availability Analysis from 1984 to 1992, EGG-FSP-10603, EG\&G Idaho, Inc., May 1993.

5-3. T. A. Heppell, "High Vacuum Pumping Systems-An Overview," Yacuum, 37, 1987, pages 593-601.

5-4. H.-P. Kabelitz and J. K. Fremerey, "Turbomoelcular Vacuum Pumps with a New Magnetic Bearing Concept," Vacuum, 38, 1988, pages 673-676.

5-5. M. Heldner and H.-P. Kabelitz, "Reliability of Turbomolecular Vacuum Pumps: A Comparison of Rolling Element and Magnetic Bearing Systems," Journal of Vacuum Science and Technology, A8, 1990, pages 2772-2777.

5-6. D. G. Goetz, "Large Turbomolecular Pumps for Fusion Research and High-energy Physics," Yacuum, 32, 1982, page 703-706.

5-7. H. G. Broe, "Vacuum Systems Associated with the AAEC's 3 MeV Accelerator," Vacuum, 18, 1968, pages 637-640.

5-8. W. Bieger et al., "Performance of a Turbomolecular Pump in a Pulsed Magnetic Field," Proceedings of the Seventh Symposium on Engineering Problems of Eusion Research, Knoxville, Tennessee, October 25-28, 1977, pages 976-980.

5-9. D. C. Arulananthan and F. P. Lees, "Some Data on the Reliability of Pressure Equipment in the Chemical Plant Environment," Intermational Journal of Pressure Vessels and Piping, 2, 1981, pages 327-338.

5-10. J. K. Jones, "Experience with Magnetic Bearing Turbomolecular Pumps," Proceedings of the Japan-U.S. Workshop P-118 on Vacuum Technologies for Eusion Devices, IPPJ-T-38, August 1-5, 1988, pages 165-173.

5-11. M. H. Hablanian, High-Yacuum Technology, A Practical Guide, Marcel Dekker, Inc., New York, 1990, pages 142, 295-301, .

5-12. S. Sarto et al., NET Safety System Study, Exhaust System. Direct Failure Final Report, SEA 4.1, ENEA/NIER, Bologna University, October 1989. 
5-13. L. C. Cadwallader, Cryogenic System Operating_Experience Review for Eusion Applications, EGG-FSP-10048, EG\&G Idaho, Inc., January 1992.

5-14. D. W. Sedgley et al., "Cryopumping for Fusion Reactors," Nuclear Engineering and Design/Fusion, 4, 1987, pages 149-163.

5-15. M. E. P. Wykes, Joint European Tonus Safety Analysis Report for the Preliminary Tritium Experiment, MW/ES/047, JET Joint Undertaking, August 7, 1991.

5-16. Manual on Reliability Data Collection for Research Reactor PSAs, IAEA-TECDOC636, International Atomic Energy Agency, January 1992, page 32.

5-17. T. D. Marshall and L. C. Cadwallader, In-Vessel UTER Tubing-Eailure Rates for Selected Materials and Coolants, EGG-FSP-10928, EG\&G Idaho, Inc., draft report December 1993, submitted to the ITER Joint Central Team.

5-18. T. S. Chou and C. Lanni, "Lifetime of Titanium Filament at Constant Current," IEEE Transactions on Nuclear Science, NS-28, 1981, pages 3323-3324.

5-19. N. C. Rasmussen et al., Reactor Safety Study--An Assessment of Accident Risks in US Commercial Nuclear Power Plants, WASH-1400, NUREG-75/014, October 1975, Appendix III, Failure Data.

5-20. J. F. O'Hanlon, A User's Guide to Vacuum Technology, second edition, John Wiley\&Sons, Inc., New York, 1989, pages 243-44, 248.

5-21. B .S. Halliday and B. A. Trickett, "Vacuum Problems on a $5 \mathrm{GeV}$ Electron Synchrotron," Joumal of Vacuum Science and Technology, 2, 1971, pages 42-45.

5-22. J. L. Ryans and D. L. Roper, Process Vacuum System Design \& Operation, McGraw-Hill Book Company, New York, 1986, chapter 9 and page 86.

5-23. Component Failure and Repair Data for Coal-Fired Power Units, EPRI AP-2071, Electric Power Research Institute, October 1981, pages 2-28 to 2-29, 2-38.

5-24. W. Unterlerchner, "Some Improvement Work on ConFlat Joints and Their Limit of Reliability in a Large-size Ultrahigh Vacuum System," Journal of Vacuum Science and Technology, A5, 1987, pages 2540-2543.

5-25. A. E. Green and A. J. Bourne, Reliability Technology, Wiley-Interscience, London, 1972, Table A.7. 
5-26. A. H. Dexter and W. C. Perkins, Component Failure-Rate Data with Potential Applicability to a Nuclear-Evel-Reprocessing_Plant, DP-1633, Savannah River Laboratory, July 1982.

5-27. L. C. Cadwallader, Investigation of Component Failure Rates for Pulsed versus Steady State Tokamak Operation, EGG-FSP-10262, EG\&G Idaho, Inc., July 1992.

5-28. B. A. Trickett, "Performance of the SRS Vacuum System," Vacuum, 37, 1987, pages 747-755.

5-29. S. R. Conviser, "The Stanford Two-Mile Linear Accelerator Vacuum System," IEEE Transactions on Nuclear Science, NS-12, 1965, pages 699-704.

5-30. H. Adam and G. Jokisch, "Vacuum Valves and Their Use in Practice," Vacuum, 37, 1987, pages 681-689.

5-31. N. Ogiwara et al., "Reliability Tests of $40 \mathrm{~cm}$ id All Metal Gate Valve and $54 \mathrm{~cm}$ id Ceramic Break for JT-60," Proceedings of the Tenth Symposium on Fusion Engineering, Philadelphia, Pennsylvania, December 5-9, 1983, pages 1058-1062.

5-32. S. R. Thomas et al., "A Large Rectangular Bellows Valve," Proceedings of the Seventh Symposium on Engineering Problems of Fusion Research, Knoxville, Tennessee, October 25-28, 1977, page 985-988.

5-33. S. A. Eide and M. B. Calley, "Generic Component Failure Data Base," PSA ' 93. Proceedings of the International Topical Meeting on Probabilistic Safety Assessment, American Nuclear Society, Clearwater Beach, Florida, January 26-29, 1993, pages 1175-1182.

5-34. S. A. Eide et al., "Component External Leakage and Rupture Frequency Estimates," PSA 93. Proceedings of the International Topical Meeting on Probabilistic Safety Assessment, American Nuclear Society, Clearwater Beach, Florida, January 26-29, 1993, pages 1171-1174.

5-35. L. C. Cadwallader and C. G. Motloch, Potential Off-Normal Events and Releases for the Tokamak Physics Experiment, EGG-FSP-10710, EG\&G Idaho, Inc., August 1993.

5-36. R. Buende, S. Fabritsiev, and V. Rybin, "Reliability of Welds and Brazed Joints in Blankets and Its Influence on Availability," Eusion Engineering and Design, 16, 1991, pages 59-72. 
5-37. Institute of Electrical and Electronics Engineers, IEEE Guide to the Collection and Bresentation of Electrical. Electronic Sensing Component. and Mechanical Equipment Reliability Data for Nuclear-Power Generating Stations, IEEE Std 5001984, December 1983, page 1327. 


\section{VACUUM SYSTEM INITIATING EVENT FREQUENCIES}

\subsection{Introduction}

This chapter contains a summary of information about published initiating event frequencies for fusion and other vacuum systems. Some of these frequencies are based on analyst judgment, others on operating experiences. For future experiments, analysts can either use these values for scoping work, or they can compare these estimates to values calculated from fault tree analysis, where the fault trees are quantified using failure rate data in the previous chapter or other sources.

\subsection{Loss of Vacuum Accident (LOVA)}

In this initiating event (IE), a large air ingress is assumed. The machine is hot, and air-wall material reactions can occur. The codeposited layer of tritium will likely be stripped away, leaving that tritium free to be driven out of the vessel by thermal expansion of air heated by the hot wall tiles. Work for the Next European Torus (NET) design, a machine smaller but comparable to ITER, gave a large LOVA initiating event frequency, to the building atmosphere, of 3.4E-08/hour.6-1 For a machine $25 \%$ available, or operating 2200 hours/year, this value is 7.5E-05/year. This IE frequency is for direct failures of the vacuum system components. Other failures, such as induced failures (for example, leakage water fracturing a hot window), and common cause failures (one cause failing many components: an earthquake, an external impact event, or others), are not considered in this value. The IE frequency is probably an upper bound estimate, so no uncertainty was reported. The reader will recall that the ITER EDA design currently calls for a robust, high vacuum cryostat around the machine, so only the ports are directly vulnerable to air ingress events. These ports could be well protected, with the use of multiple windows and structural reinforcement. Thus, the ITER value may be lower than this estimate for a LOVA.

Other vacuum system (vacuum vessel) large breach failure frequency estimates have been based on the experience of thin-walled tanks, 6-2 and analyst judgment. $6-3$ The values vary around $1 \mathrm{E}-03$ to $1 \mathrm{E}-04 /$ year. Recent work by Wu et al.6-4 indicates that for nuclear pressure vessels, there has not been enough operating experience to estimate accurate failure rates, so only probabilistic fracture mechanics can give a good answer. Wu et al. estimate that a boiling water reactor pressure vessel breach failure rate is actually on the order of 1E-08/year. Fusion vacuum vessels might also need to be treated with probabilistic fracture mechanics. The vacuum vessel large breach frequency must be investigated further, but as a first approximation for a device such as ITER, the NET estimate of 3.4E-08/hour is the most reasonable value to use for the conceptual stage of fusion designs. 


\subsection{Loss of Coolant Accident (LOCA)}

A small in-vessel loss of cooling water or other fluid could be very detrimental. Water will react with the wall tiles and generate hydrogen, a possible explosive.6-5 Several crude estimates for frequencies of in-vessel coolant line breaks have been made for ITER based on operating experiences of similar material tubes with the likely coolants over a 2200 hour operating year. These estimated IE frequencies for small LOCAs are:6-6

high pressure water

helium

liquid metals 2/year; error estimate of 10

5E-04/year, error estimate of 10

0.2/year; error estimate of 10

The work from reference 6-6 has been refined with more detailed tubing failure rate investigations. ${ }^{6-7}$ These more detailed failure rates have been carefully adjusted for the fusion environment and coolant-specific concerns. The same assumptions about length of coolant tubing and hours of yearly operation are used. For water coolant and a variety of materials, the frequency is between 0.1 to $4 /$ year. For the same materials with helium coolant, the frequency is 0.1 to $2 /$ year, and similarly, for liquid lithium coolant, the frequency varies between 0.1 to $8 /$ year. These ranges show that, for the materials considered here (stainless steel, ferritic steel, and inconel), the differences are not significant. The results also show that ITER must be able to mitigate this coolant leakage event. Other ideas, such as duplex (two tube walls) tubing, might give lower failure rates by perhaps a factor of 10 . A frequency decrease to account for high level quality assurance might be a factor of 3, perhaps with exceedingly stringent assurance then a factor of 10 . Even using the factor reductions for duplex tubing and detailed quality assurance, the estimates still indicate a potential problem over the 10 (or more) year life of the machine. These estimates treat only tubing material failures. These estimates do not account for runaway electrons or other common mode events. Perhaps other approaches besides cooling tubes can be explored for ITER.

Large LOCA events would be less frequent than the small LOCA. In other work for NET, a value of $1 E-07 /$ hour for a large leak from any large coolant manifold was selected, for an in-vessel large LOCA IE frequency of 1E-05/hour. 6-8 This frequency would give $0.02 /$ year for 2200 operating hours per calendar year. The value is somewhat conservative in comparison with piping failure rates used in the literature for fission reactor systems. Perhaps that value has been weighted for the more harsh fusion conditions of radiation damage, thermal cycling, and vibration.

\subsection{Loss of Flow Accident (LOFA)}

For small in-vessel tubes, tube plugging is of the same failure rate as tube

rupturing, which are generally a factor of 10 below tube leakage values. ${ }^{6-7}$ That accounts 
for in-vessel LOFA events. The in-vessel LOFA frequency would be roughly an order of magnitude lower than the in-vessel LOCA frequencies given above.

Other LOFA fault events outside the vessel could be valve inadvertent closure, pump failure, or loss of power to the pump. Considering these events for various coolants, and simple flow circuits ( $500 \mathrm{~m}$ piping, one pump, one valve), has yielded preliminary results. Some of the assumptions were that coolant chemistry is controlled very well, the piping and tubing have been thoroughly checked for foreign materials, and valves and pumps were as reliable as those in fission applications with the same materials and coolants. For an ITER-like machine, the frequency of an ex-vessel loss of flow accident would be: $6-6$
high pressure water
4E-05/year; error estimate of 12
helium
9E-06/year; error estimate of 30
liquid metals
2E-03/year; error estimate of 10

These values are relatively close in magnitude, and are in the unlikely or very unlikely events range.

\subsection{Other Events}

For a machine like ITER, with a robust cryostat, there is another concern. If the cryostat pressurizes without relieving to a vent line or the torus hall, there could be pressure stresses generated on the vacuum vessel and its ports. Stresses such as these have been analyzed for some types of piping. ${ }^{6-9}$ If the vessel were to breach by buckling, a port might shift position, breaching its seal through the cryostat. The port breach might allow the overpressure to escape, along with radioactive effluents from the breached vessel. This event should be a very low frequency, since an overpressure situation must first exist in the cryostat, and then the overpressure should only serve to actuate the simple relief devices (rupture disks, blow out panels, etc.) present on any cryostat as part of prudent design for cryogenic systems. 
6-1. A. Boschi et al., "Risk Evaluation of the In-Vessel Plant Area of a NET Type Tokamak Machine: Direct, Induced and Common Cause Failures," Proceedines of the Thirteenth Symposium on Fusion Engineering, Knoxville, Tennessee, October 2-6, 1989, pages 1108-1111.

6-2. D. C. Arulanantham and F. P. Lees, "Some Data on the Reliability of Pressure Equipment in the Chemical Plant Environment," Intemational Jourmal of Pressure Yessels and Biping, 2, 1981, pages 327-338.

6-3. L. C. Cadwallader and C. G. Motloch, Potential Off-Normal Events and Releases for the Tokamak Physics Experiment, EGG-FSP-10710, EG\&G Idaho, Inc., August 1993.

6-4. W. F. Wu, C. S. Shin, and C. H. Tai, "A Reliability Assessment of Reactor Pressure Vessels," International Journal of Pressure Vessels and Piping, 57, 1994, pages 77-84.

6-5. P. L. Goranson, "Hydrogen/Hydrocarbon Explosions in the ITER Vacuum Vessel," Eusion Technology, 21, 1992, pages 2041-2045.

6-6. L. C. Cadwallader, Investigation of Selected Accident Frequencies for Helium. Water. and Liquid Metal UTER Coolants, ITER/US/93/EN/SA-3, January 27, 1993.

6-7. T. D. Marshall and L. C. Cadwallader, In-Vessel Tubing Failure Rates for Selected Materials and Coolants, EGG-FSP-10928, March 1994.

6-8. G. Cam'ji et al., "Risk Evaluation of Critical In-Vessel Accident Sequences for a Next Step Tokamak Machine," Eusion Engineering_and Design, 17, 1991, pages 395-401.

6-9. G. D. Galletly and S. James, "Inter-ring Buckling of Welded Ring-stiffened Cylindrical Shells Subjected to External Pressure," Proceedings of the Institution of Mechanical Engineers. Part E, 203, 1989, pages 101-114. 

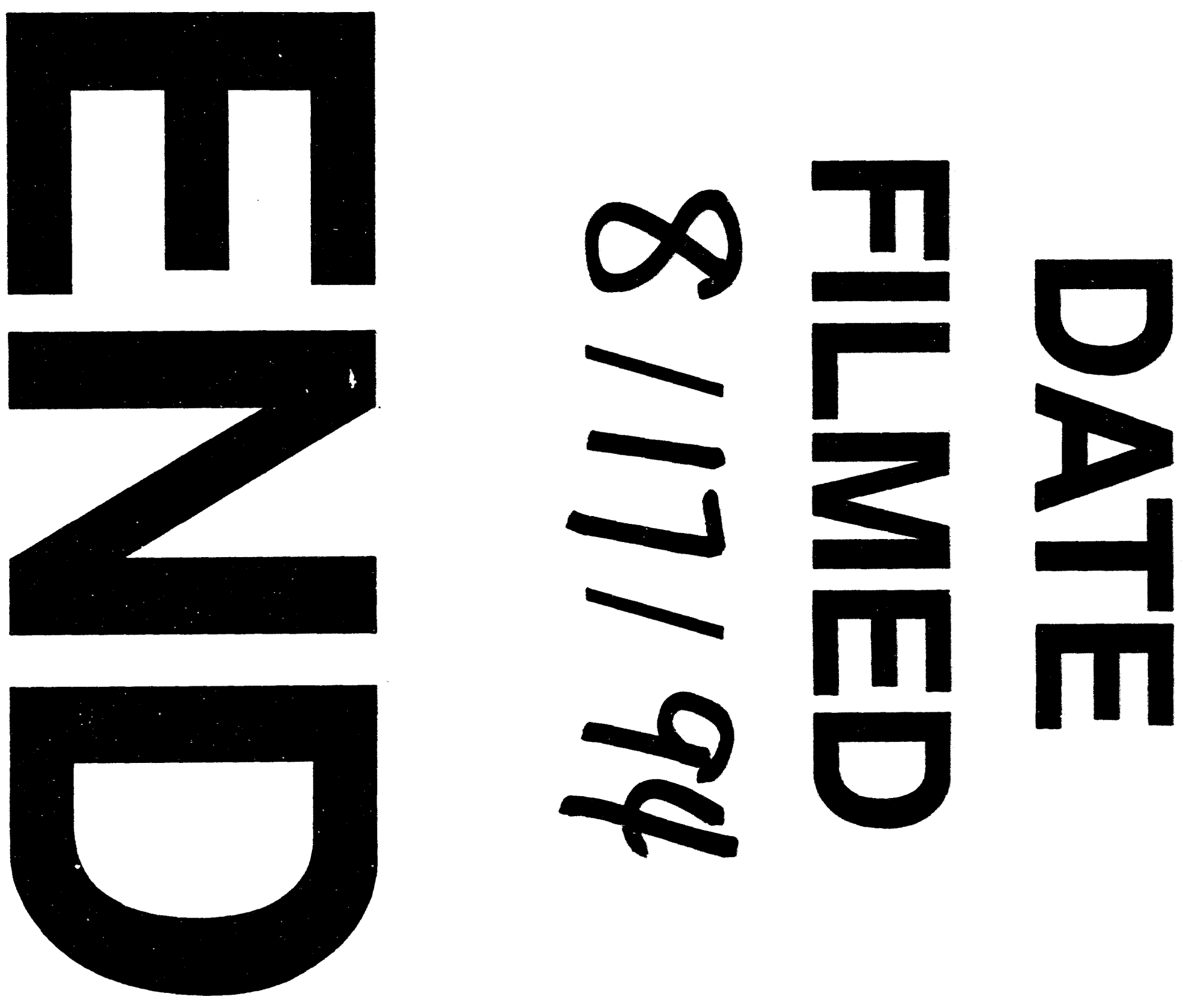


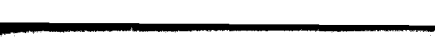

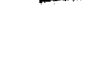
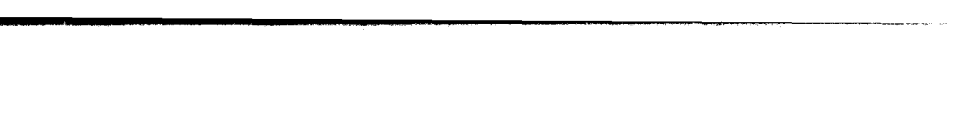
$-$ 